\title{
Classical Major Histocompatibility Complex Class I Molecules in Motoneurons: New Actors at the Neuromuscular Junction
}

\author{
Sebastian Thams, ${ }^{1}$ Petter Brodin, ${ }^{2 \star}$ Stefan Plantman, ${ }^{1 *}$ Robert Saxelin, ${ }^{1}$ Klas Kärre, ${ }^{2}$ and Staffan Cullheim ${ }^{1}$ \\ ${ }^{1}$ Department of Neuroscience and ${ }^{2}$ Strategic Research Center for Studies of Integrative Recognition in the Immune System, Department of Microbiology, \\ Tumor and Cell Biology, Karolinska Institutet, SE-171 77 Stockholm, Sweden
}

\begin{abstract}
Major histocompatibility complex (MHC) class I molecules have fundamental functions in the immune system. Recent studies have suggested that these molecules may also have non-immune functions in the nervous system, in particular related to synaptic function and plasticity. Because adult motoneurons express mRNAs for MHC class I molecules, we have examined their subcellular expression pattern in vivo and their role for the synaptic connectivity of these neurons. We observed immunoreactivity for classical MHC class I (Ia) protein in motoneuron somata, but the predominant expression was found in axons and presynaptically at neuromuscular junctions (NMJs). Peripheral nerve lesion induced a strong increase of motoneuron MHC class $\mathrm{Ia}\left(\mathrm{H} 2-\mathrm{K}^{\mathrm{b}} / \mathrm{D}^{\mathrm{b}}\right) \mathrm{mRNA}$, indicating a role for MHC class Ia molecules during regeneration. Accordingly, there was an accumulation of MHC class Ia proteins at the cut ends and in growth cones of motor axons after lesion. In $K^{b-/} D^{b-1-}$ mice (lacking MHC class Ia molecules), the time course for recovery of grip ability in reinnervated muscles was significantly delayed. Muscles from $K^{b-1-} D^{b-1-}$ mice displayed an increased density and a disturbed distribution of NMJs and fewer terminal Schwann cells/NMJ compared with wild-type mice. A population of Schwann cells in sciatic nerves expressed the paired Ig receptor B, which binds to MHC class I molecules. These results provide the first evidence that neuronal MHC class Ia molecules are present in motor axons, that they are important for organization of NMJs and motor recovery after nerve lesion, and that their actions may be mediated via Schwann cells.
\end{abstract}

\section{Introduction}

There is accumulating evidence that immune molecules are used by neurons and glia in the CNS to modulate synaptic function and plasticity, in particular during development (Huh et al., 2000; Oliveira et al., 2004; Syken et al., 2006; Stevens et al., 2007; Zohar et al., 2008). Because synaptic dysfunction is a fundamental feature of neurodevelopmental and neurodegenerative diseases, it is important to understand how immune molecules in CNS cells exert their effects on synapses.

Examples of immune molecules expressed by neurons include the major histocompatibility complex (MHC) class I proteins and associated molecules necessary for peptide loading [transporter associated with antigen presentation (TAP)] and surface expression $\left[\beta_{2}\right.$-microglobulin $\left.\left(\beta_{2} \mathrm{~m}\right)\right]$ (Kimura and Griffin, 2000). Rat spinal motoneurons constitutively express mRNAs for MHC class I and $\beta_{2} \mathrm{~m}$ (Lindå et al., 1998).

\footnotetext{
Received Feb. 27, 2009; revised Sept. 8, 2009; accepted Sept. 11, 2009.

This study was supported by the Swedish Research Council, the Brain Foundation, the Marcus and Amalia Wallenbergs Foundation, the Marianne and Marcus Wallenbergs Foundation, Friends of Karolinska Institutet, and Karolinska Institutet. We thank Anita Bergstrand and Johan Zelano for technical assistance.

*P.B. and S.P. contributed equally to this work.

The authors declare no competing financial interests.

Correspondence should be addressed to either Sebastian Thams or Staffan Cullheim, Department of Neuroscience, Retzius väg, Karolinska Institutet, SE-171 77 Stockholm, Sweden. E-mail: sebastian.thams@ki.se or staffan.cullheim@ki.se.

D0I:10.1523/JNEUROSCI.0981-09.2009

Copyright $\odot 2009$ Society for Neuroscience 0270-6474/09/2913503-13\$15.00/0
}

One classical response to lesion of motor axons is the shedding of synapses from the cell surface of severed motoneurons (Blinzinger and Kreutzberg, 1968). We have shown that mice lacking the $\beta_{2} \mathrm{~m}$ gene, thereby failing to express MHC class I molecules at the cell surface, display a more extensive synaptic elimination from the cell bodies of axotomized spinal motoneurons compared with wild-type (WT) mice (Oliveira et al., 2004). Moreover, these animals displayed an impaired axonal regeneration after nerve crush (Oliveira et al., 2004). Whether these responses are governed by MHC class I molecules in motoneurons or glia is not known, however. The function of MHC class I molecules in motoneurons is therefore still enigmatic. MHC molecules are usually studied in hematopoietic cells with a relatively simple symmetric shape and homogenous distribution of cell surface molecules. Conversely, motoneurons have a complex asymmetric morphology, with a cell body and dendrites contacted by up to 100,000 presynaptic terminals (Ulfhake and Cullheim, 1988) and an axon that can grow 20,000 times the diameter of the cell body, eventually reaching the muscle, forming neuromuscular junctions (NMJs). Moreover, the MHC class I gene family encodes classical (Ia) and nonclassical (Ib) MHC proteins and the proteins expressed in and functionally affecting motoneurons could be of either type.

The primary aims of this study were to identify whether classical MHC class Ia proteins are expressed by motoneurons in vivo, their subcellular location, and their roles for synaptic function and plasticity after axon lesion. We initially hypothesized MHC 
class I expression in the postsynaptic membrane of the cell body and dendrites, given the previous observations on synaptic elimination. Using an antibody to the classical H2-D ${ }^{\mathrm{b}}$ MHC Ia molecule, we surprisingly observed the strongest immunoreactivity (IR) for MHC class Ia protein in motor axons and presynaptically at NMJs rather than in the parts of the motoneuron receiving synaptic input. Therefore, the additional focus of this study was to reveal the role of MHC class Ia for NMJ plasticity, to investigate functional motor disturbances in the absence of MHC class Ia molecules and to identify possible MHC class Ia receptors and their cellular location in the peripheral nerve and at the NMJ.

\section{Materials and Methods}

Animals. Animals were bred and maintained at the Department of Microbiology, Tumor and Cell Biology (Karolinska Institutet, Stockholm, Sweden). Young adult, age- and gender-matched animals were used, and all experimental procedures were approved by the local ethical committee (Stockholms Norra Djurförsöksetiska Nämnd). C57BL/6 (B6) mice served as WT strain. B6. $\beta 2 m^{-1-}\left(\right.$ B6.129P2- $\beta_{2} m^{\text {tmlUnc }}$ stock number 002087; $\beta_{2} m^{-1-}$ ) and B6.TAP1 ${ }^{-1-}$ mice (B6.129S2-Tap ${ }^{\text {tmArp }}$ stock number 002944; $\mathrm{TAP1}^{-1-}$ ) were purchased from The Jackson Laboratory and backcrossed for 6-11 generations on the C57BL/6 (B6) background. To generate B6.TAP1 $1^{-1-} \beta_{2} m^{-1-}$ double-mutant mice, B6. $\beta_{2} m^{-1-}$ and B6.TAP1 $1^{-1-}$ mice $\left(T A P 1^{-1-} \beta_{2} m^{-1-}\right)$ were mated, and the offspring were subsequently intercrossed and genotyped. $B 6 \cdot K^{b-/-}$, $B 6 . D^{b-1-}$, and $B 6 . K^{b-1-} D^{b-1-}$ mice were generated as described previously (Pascolo et al., 1997; Vugmeyster et al., 1998; Pérarnau et al., 1999) and were a kind gift from F. A. Lemonnier (Pasteur Institute, Paris, France). B6.RAG1 $1^{-/-}$mice $\left(R A G 1^{-/-}\right)$were used as an immunodeficient strain. MHC class-deficient mice will be denoted by their allelic name throughout the paper (i.e., $K^{b-/-}, D^{b-/-}, K^{b-/-} D^{b-/-}$ ). Murine MHC class I is termed H2, and the following capital letter (in this case $\mathrm{K}$ or D) indicates the specific gene in the MHC class I gene family. The superscript letter indicates the haplotype. The subset of MHC class I proteins expressed is strain specific. C57BL/6 mice express the $\mathrm{H} 2-\mathrm{K}$ and $\mathrm{H} 2-\mathrm{D}$ genes of the "b" haplotype as well as nonclassical MHC class I genes.

Surgery and tissue handling. Animals were anesthetized with intraperitoneal injections of Dormicum (Roche) and Hypnorm (VetaPharma) in water. The left sciatic nerve was ligated and transected or crushed as described previously (Oliveira et al., 2004). Unoperated mice of the same litters were used as controls. Animals were allowed to survive for $7-45 \mathrm{~d}$ before they were killed, followed by perfusion with either $0.01 \mathrm{M}$ PBS for in situ hybridization (ISH) or Tyrodes's buffer, followed by Lana's fixative ( $4 \%$ Formalin and $0.4 \%$ picric acid in $0.16 \mathrm{M} \mathrm{PBS}, \mathrm{pH} 7.2)$ at $20^{\circ} \mathrm{C}$ for immunohistochemistry. The lumbar spinal cord, sciatic nerve, the triceps surae muscle, or the diaphragm were quickly dissected out. For in situ hybridization, the tissue was immediately freshly frozen on dry ice and mounted in OCT (Tissue Tek; Sakura). For immunohistochemistry, the tissue was left in the same fixative for $90-180 \mathrm{~min}$ or overnight at $4^{\circ} \mathrm{C}$, rinsed, and stored $24 \mathrm{~h}$ in $10 \%$ sucrose with $0.1 \%$ sodium azide in $0.01 \mathrm{~m}$ PSB at $4^{\circ} \mathrm{C}$ for cryoprotection, before mounting in OCT. The spinal cords, brainstems, sciatic nerves, and muscles were cut in 14,30 , or 120 $\mu \mathrm{m}$ sections.

In situ hybridization and semiquantitative analysis. Oligonucleotides were synthesized (CyberGene), and ISH was performed as described previously (Dagerlind et al., 1992). Because of a high degree of crossreactivity between $\mathrm{H} 2-\mathrm{K}^{\mathrm{b}}$ and $\mathrm{H} 2-\mathrm{D}^{\mathrm{b}}$, a pan-class Ia probe was synthesized (GGAGCCTGGAGCCAGAGCATAGTCCCCTCCTTTTCCACCTGTGTTTCT; GenBank accession number AY989882.1). $K^{b-/-}, D^{b-1-}$, and $K^{b-/-} D^{b-/-}$ mice were used to check the specificity of the probes. One $\beta_{2}$-microglobulin-specific probe (CAGGCGTATGTATCAGTCTCAGTGGGGGTGAATTCAGTGTGAGCCAGG; GenBank accession number X01838.1) was also synthesized, and its specificity was verified using B6. $\beta_{2} m^{-1-}$ mice. Semiquantitative measurements of the ISH signal 2 weeks after sciatic nerve transection (SNT) $(n=3)$ were performed as described previously (Piehl et al., 1995; Zelano et al., 2006).

Immunohistochemistry. Frozen spinal cord, nerve, or muscle sections of 14 or $30 \mu \mathrm{m}$ in thickness were thawed, dried, and dehydrated in $0.01 \mathrm{~m}$
PBS. Free-floating muscle sections of $90-120 \mu \mathrm{m}$ in thickness were rinsed in $0.01 \mathrm{M}$ PBS. Sections on objective slides and free-floating sections were then blocked and permeabilized for $30 \mathrm{~min}$ in room temperature (RT) in 5\% donkey serum and $0.3 \%$ Triton X-100 diluted in $0.01 \mathrm{M}$ PBS. Primary antibodies were diluted in $0.01 \mathrm{M}$ PBS with $5 \%$ donkey serum and $0.3 \%$ Triton X-100. Sections were incubated with primary antibodies overnight at $4^{\circ} \mathrm{C}$. The next day, the sections were washed two times for $10 \mathrm{~min}$ in $0.01 \mathrm{M}$ PBS and then incubated with cyanine 2 (Cy2)-, Cy3-, or Cy5-conjugated donkey secondary antibodies (1:200 for Cy2 and Cy5 and 1:500 for Cy3; Jackson ImmunoResearch) or an Alexa-488conjugated $\alpha$-bungarotoxin ( $\alpha$-btx) (1:200; Invitrogen) for $60 \mathrm{~min}$ in RT. The sections were then rinsed three times for $5 \mathrm{~min}$ in $0.01 \mathrm{~m}$ PBS, then mounted in a mixture of glycerol/PBS, and coverslipped. Whole diaphragms were rinsed in $0.01 \mathrm{~m}$ PBS and then blocked and permeabilized for 60 min at RT with 5\% donkey serum and 0.5\% Triton X-100 in $0.01 \mathrm{M}$ PBS. Diaphragms were then incubated with a synaptophysin (syph) antibody (1:100; Zymed) overnight in $4^{\circ} \mathrm{C}$, rinsed in $0.01 \mathrm{M}$ PBS with 5\% Triton X-100 two times for $30 \mathrm{~min}$, and then incubated overnight at $4^{\circ} \mathrm{C}$ with a Cy3-conjugated secondary antibody and an Alexa-488 conjugated $\alpha$-btx. The following day, diaphragms were rinsed two times for $30 \mathrm{~min}$ in $0.01 \mathrm{M}$ PBS with $5 \%$ Triton X-100, mounted in glycerol/ PBS, and coverslipped. The sections were analyzed with a Carl Zeiss LSM 5 Exciter confocal microscope.

For MHC class I immunohistochemistry with the ER-HR 52 antibody, a modified protocol was used. Both fresh frozen postfixed (Lana's fix) and perfused postfixed (Lana's fix) tissue was tested. Perfused postfixed tissue gave better results than fresh frozen, and a postfixation time of 60 min was determined to be the most suitable for the protocol used. We then titrated a suitable concentration of detergent. We obtained consistent results at $0.1 \%$ Tween 20 and $0.05 \%$ Triton X-100. Because the latter worked better with the other antibodies used for double or triple labeling, this type of detergent and concentration was used.

The following primary antibodies were used: rabbit anti-synaptophysin (1:100), rabbit anti-GFAP (1:200), rabbit anti-S100 (1:500), and rabbit anti-PGP9.5 (1:500) all from Dako; mouse monoclonal anti-microtubuleassociated protein 2 (MAP2) (1:500), rabbit anti-neurofilament 200 (1:1000), and rabbit anti-vesicular acetylcholine transporter (VAChT) (1: 1000) from Sigma-Aldrich; rat monoclonal anti-MHC class I ER-HR 52 clone (1:100) from Abcam; $\alpha$-btx conjugated with Alexa-488 (5 $\mu \mathrm{g} / \mathrm{ml})$ from Invitrogen; rat monoclonal anti-paired Ig receptor B (PIR-B) (1:100 from) from R \& D Systems; rabbit anti-Ibal (1:500) from Wako; and a antisynaptophysin (1:100) from Zymed.

Image analysis. For the muscle montages, montages of $30 \mu \mathrm{m}$ sections of the lateral gastrocnemiums muscles (GCM) were created from confocal images captured at $10 \times$ objective at zoom 0.5 , which were put together, and the pattern of the $\alpha$-btx staining was traced using the Live Trace/Live Paint application in Adobe Illustrator CS3 (Adobe Systems). The threshold was set so that as much of the $\alpha$-btx staining as possible was included without tracing background staining. The tracing threshold was kept constant for WT and knock-out (KO) muscle montages. The traced staining pattern was converted into black pixels, and the contour of the muscle sections was delineated on the original montage and put as a gray-colored background. Montages from whole diaphragms were created from flattened $z$-stacks of the entire depth of the muscles, and $\alpha$-btx staining pattern was traced as described above.

For NMJ morphometry, NMJs were visualized with $\alpha$-btx [acetylcholine receptor (AChR) receptor clusters], $\mathrm{S} 100 \beta$ [Schwann cell (SC) marker], and TOTO-3 (cell nuclei) (supplemental Fig. S3, available at www.jneurosci.org as supplemental material). All NMJs that appeared to be entirely contained within the section thickness were analyzed. Confocal $z$-stacks with an interval of $0.6 \mu \mathrm{m}$ were captured for individual NMJs, and projections in three dimensions were made with the LSM browser Zeiss or WCIF ImageJ. A terminal Schwann cell (TSC) was defined by a TOTO-3-positive nucleus surrounded by S100 $\beta$-positive cytoplasm overlying $\alpha$-btx-positive clusters (supplemental Fig. S1, available at www.jneurosci.org as supplemental material). Six to eight NMJs per muscle and animal were analyzed from uninjured animals $(n=5$ for WT, $n=7$ for $K^{b-1-} D^{b-/-}$ ) and animals subjected to a sciatic nerve crush (SNC) at 30 d postoperatively (dpo) $\left(n=6\right.$ for WT and $\left.K^{b-1-} D^{b-/-}\right)$. The 
AChR cluster area was estimated for each NMJ using WCIF ImageJ, and the area was then divided with the counted number for the same NMJ.

Flow cytometry. To characterize the specificity of the ER-HR 52 antibody (1:100), we performed fluorescence-activated cell sorting (FACS) on blood from C57BL/6, $K^{b-1-}, D^{b-1-}, K^{b-1-} D^{b-1-}$, and TAP1 $1^{-1-} \beta_{2} m^{-1-}$ mutants ( $n=4$ for all strains). A secondary goat anti-rat IgG (heavy and light) Alexa-647 (20 $\mu \mathrm{g} / \mathrm{ml}$; Invitrogen) served as a reference. For FACS on Schwann cells, sciatic nerves were removed from newborn mice at day 4-5, cleaned from endoneurium, and teased apart before being chemically dissociated in $0.25 \%$ trypsin. Enzyme activity was blocked by addition of $10 \%$ heat-inactivated fetal bovine serum. The nerves were then mechanically dissociated using a fire-polished Pasteur pipette. The cell suspension was layered on top of a 15\% BSA cushion and centrifuged ( 3 $\mathrm{min}, 800 \mathrm{rpm}$ ), to remove cellular debris. In the final cell suspension, $75-80 \%$ of the cells were S100-positive and thus determined to be Schwann cells. Single-cell suspensions were then stained with a rabbit anti-P75 antibody (1:500; Promega) together with an anti-rabbit allophycocyanin secondary (Jackson ImmunoResearch) and a rat antiPIR-A/B antibody (1:100; BD Biosciences Pharmingen) or a rat antiPIR-B (1:1000; R \& D Systems) together with 70 ng of anti-rat FITC secondary (Caltag-Medsystems). Samples were analyzed using a FACSAria (BD Biosciences) and analyzed using the FlowJo Software (TreeStar).

In vitro experiments. The motoneuron-like cell line MN-1 (kindly provided by Dr. Carlos Ibanez, Karolinska Institutet, Stockholm, Sweden) was cultured and treated for $24 \mathrm{~h}$ with INF- $\gamma(50 \mathrm{U} / \mathrm{ml})$, fixed with Lana's fixative for $15 \mathrm{~min}$, and then processed for immunohistochemistry.

Analysis of intact and reinnervated muscles. In intact GCM from WT and mutant mice, the mean muscle fiber cross-sectional area and number of synaptic AChR clusters were analyzed in six longitudinal midsections/ muscle. The AChR cluster density was calculated for each section by dividing the number of clusters/section with the area of the muscle section. This analysis was done blindly with regard to phenotype, operation/ control, and survival time. Diaphragm were dissected out and then processed for immunohistochemistry as whole-mount preparation. $z$-stacks through the entire depth of the diaphragm were captured with a section interval of $1-2 \mu \mathrm{m}$ and mounted together as maximum projections. In the right hemidiaphragm, serially acquired confocal $z$-stacks through the entire thickness of the muscle covering the synaptic band were analyzed, and the mean number of AChR clusters per millimeter of synaptic band length was calculated for each $z$-stack and then for the whole synaptic band. The mean muscle fiber cross-sectional area was calculated in 300-450 muscle fibers per muscle in midsections from both intact and reinnervated GCM using WCIF ImageJ. TSC analysis was performed with a modified protocol described previously (Hess et al., 2007).

Behavioral testing. To study functional muscle recovery, mice were subjected to an SNC, and the return of grip function was assessed every 3-4 d during the recovery period. The mice were let to grip the cage lid while held by the tail, suspending the hindlimbs in the air. A grip reflex was elicited by placing a metal rod on the sole of the feet. The metal rod was then pulled away until the grip was lost. This procedure was repeated five times per session, and the injured foot was compared with the intact one ( $n=10$ for WT and $n=7$ for $\left.K^{b-/-} D^{b-1-}\right)$. Grip ability was expressed as "inability to grip," "insufficient grip," or "similar to contralateral foot." All testing was made by one main observer, blind to genotype and result from the last session, and also intermittently confirmed by four different independent co-observers blinded to genotype and experiment.

Confocal analysis of dissociated muscle fiber bundles. Animals were perfused as described above. The GCM dissected out and incubated in a $37^{\circ} \mathrm{C}$ water bath for $2.5 \mathrm{~h}$ in $0.01 \mathrm{M} \mathrm{PBS}$ containing collagenase type 1A (Sigma-Aldrich) at a concentration of $2.5 \mathrm{mg} / \mathrm{ml}$. The muscles were divided into larger pieces and incubated overnight in Alexa-488conjugated $\alpha$-bungarotoxin. The muscle pieces were then mechanically separated into gradually smaller bundles using fine tweezers. Muscle fiber bundles consisting of 2-10 fibers were mounted in glycerol on objective slides that were coverslipped. The muscle fibers were then examined in a confocal microscope.

Statistical analysis. Gaussian distribution could be assumed for all data, as determined using the Column Statistics function in GraphPad Prism 4.0 (GraphPad Software), and the variances were determined to be equal using an $F$ test. A two-tailed Student's $t$ test with a $95 \%$ confidence interval was therefore used for all statistical analysis.

\section{Results}

\section{Upregulation of MHC class Ia and $\boldsymbol{\beta}_{2} \mathrm{~m}$ mRNAs in the spinal cord after axotomy}

The expression of MHC class I and $\beta_{2}$ m mRNAs in the lumbar spinal cord was studied at 1 and 2 weeks after an SNT. Large dorsolateral ventral horn neurons were considered to be sciatic motoneurons, and small round dispersed cells were considered to be surrounding glia, as revealed in counterstained sections (Fig. $1 G-I, M-O)$. At 1 week after sciatic nerve transection, $\mathrm{H} 2-\mathrm{K}^{\mathrm{b}} / \mathrm{D}^{\mathrm{b}}$ and $\beta_{2} \mathrm{~m}$ mRNAs were strongly upregulated in the affected sciatic motor nuclei (Fig. $1 A, B, E, K$ ). Semiquantitative measurements of the in situ hybridization signal in axotomized motoneurons showed an approximately fivefold increase in mRNA levels for MHC class Ia and a ninefold increase in $\beta_{2}$ m mRNAs $(n=3)$ (Fig. 1C) compared with contralateral uninjured motoneurons, expressing constitutive levels (Fig. $1 D, J$ ). After axotomy, not only motoneurons, but also surrounding glia, upregulated MHC class Ia and $\beta_{2} \mathrm{~m}$ mRNAs (Fig. $1 E, H, K, N$ ). The neuropil including surrounding glia in the contralateral side to the injury did not show any labeling above background levels (Fig. $1 D, J$ ). Notably, intact as well as axotomized motoneurons were heterogenous in mRNA levels for both probes, and some motoneurons even appeared to be negative (Fig. $2 A-D$ ).

As expected, the MHC class Ia probe gave negative results in lumbar spinal cord sections from $\mathrm{K}^{b-/-} D^{b-/-}$ mice subjected to an SNT (Fig. $1 F$ ) but gave clear labeling in both $K^{b-/-}$ (Fig. $2 A, C)$ and $D^{b-1-}$ mice (our unpublished data). Similarly, the $\beta_{2} \mathrm{~m}$ probe gave negative results on sections from operated $\beta_{2} m^{-1-}$ mice (Fig. $1 L$ ).

\section{Search for $\mathrm{H} 2-\mathrm{D}^{\mathrm{b}}$-IR in motoneuron cell bodies in the spinal cord}

The MHC class Ia probe used in WT animals did not distinguish between $\mathrm{H} 2-\mathrm{D}^{\mathrm{b}}$ and $\mathrm{H} 2-\mathrm{K}^{\mathrm{b}}$ mRNAs. In contrast, the ER-HR 52 antibody showed strong exclusive affinity for H2- $\mathrm{D}^{\mathrm{b}}$ (supplemental Fig. S1, available at www.jneurosci.org as supplemental material). In situ hybridization of spinal cord sections from normal and operated $K^{b-/-}$ animals with the MHC class Ia probe revealed mRNA labeling in motoneurons that was similar to that of WT animals, thereby confirming that $\mathrm{H} 2-\mathrm{D}^{\mathrm{b}}$ mRNA is present in motoneurons and subsequently upregulated after axotomy. Like in WT mice, labeling was observed in uninjured motoneurons (Fig. $2 \mathrm{~A}$ ) and in both motoneurons and surrounding glia at 1 and 2 weeks after SNT (Fig. 2C). Like in WT spinal cords, there was a heterogenous staining intensity in both uninjured and injured motoneurons (Fig. $2 A, C$ ). In resemblance to the $\mathrm{H} 2-\mathrm{D}^{\mathrm{b}}$ mRNA labeling, a heterogenous neuronal staining was seen for $\mathrm{H} 2-\mathrm{D}^{\mathrm{b}}$-IR in spinal cords from uninjured and operated animals (Fig. 2E,G). The sciatic motoneurons were identified by their dorsolateral location in the ventral horn of the lumbar spinal cord, by their large size, and by costaining with VAChT (Fig. $2 F, H)$. Notably, we could not detect a clear upregulation of $\mathrm{H} 2$ $\mathrm{D}^{\mathrm{b}}$-IR in motoneuron cell bodies in the spinal cord after axotomy that corresponded to the increase in $\mathrm{H} 2-\mathrm{D}^{\mathrm{b}}$ mRNA seen with in situ hybridization. The strong halo-like staining surrounding 
axotomized motoneurons (Fig. 2G) was colocalized with the microglial marker Iba1 (supplemental Fig. S2 A-C, available at www.jneurosci.org as supplemental material). To detect a possible localization of $\mathrm{H} 2-\mathrm{D}^{\mathrm{b}}$-IR in motoneuron dendrites, we performed a colocalization analysis in $z$-stacks from spinal cord sections colabeled with the ER-HR 52 antibody and MAP2 (dendritic marker) (supplemental Fig. S2 $D-H$, available at www.jneurosci. org as supplemental material). This analysis did not reveal any $\mathrm{H}_{2}-\mathrm{D}^{\mathrm{b}}$-IR in motoneuron dendrites. One should still take into consideration that putative dendritic MHC class I protein clusters could be hard to visualize in vivo in the case of axotomy because of the intricate arborization of the dendrites intertwined with surrounding MHC class I-positive microglial processes.

\section{Expression of neuronal MHC class I} molecules in motor axons

The lack of increase in $\mathrm{H} 2-\mathrm{D}^{\mathrm{b}}$-IR in somata of axotomized motoneurons suggested that the $\mathrm{H} 2-\mathrm{D}^{\mathrm{b}}$ proteins may be distributed into axon-like processes. This possibility was first studied in a motoneuron-like cell line, termed MN1 (SalazarGrueso et al., 1991; Paratcha et al., 2001). The MN1 cells were costained with the choline acetyl transferase (ChAT) (Fig. $2 I, K$ ) and the ER-HR 52 antibody (Fig. $2 \mathrm{H}, \mathrm{J}) . \mathrm{H} 2-\mathrm{D}^{\mathrm{b}}$-IR was seen in untreated cultures (Fig. 2I) and after treatment with interferon- $\gamma$ (IFN- $\gamma$ ) (Fig. $2 K$ ). Moreover, H2-D ${ }^{b}$-IR was often seen in neurites and growth cone-like processes (Fig. $2 J, K$ ).

These observations led us to explore the possibility that MHC class I molecules produced in motoneuron somata are transported peripherally in motor axons in vivo. Accordingly, we detected axonal $\mathrm{H} 2-\mathrm{D}^{\mathrm{b}}$-IR in the uninjured sciatic nerve and the proximal nerve stump at 1 and 2 weeks after SNT in WT mice. In the uninjured sciatic nerve, $\mathrm{H} 2-\mathrm{D}^{\mathrm{b}}$-IR was observed in a subpopulation of axons colabeled with the axonal marker PGP9.5 (Fig. 3A). PGP9.5 does not distinguish between different types of axons present in the nerve (i.e., motor, sensory, and autonomic), but, judging from the size of the $\mathrm{H} 2-\mathrm{D}^{\mathrm{b}}$-positive axons, we expected some of them to be motor axons. In the proximal stump of the transected sciatic nerve, multiple cell types displayed intense $\mathrm{H} 2-\mathrm{D}^{\mathrm{b}}$-IR. We mainly focused on identifying neural cells in this study and did not costain for various immunological cells and fibroblasts, which infiltrate the nerve stumps and are likely to express MHC class I molecules. In resemblance to the uninjured nerve, we found PGP9.5 and neurofilament (NF)-positive axons, preferentially large in caliber, which were intensely stained for $\mathrm{H} 2-\mathrm{D}^{\mathrm{b}}$
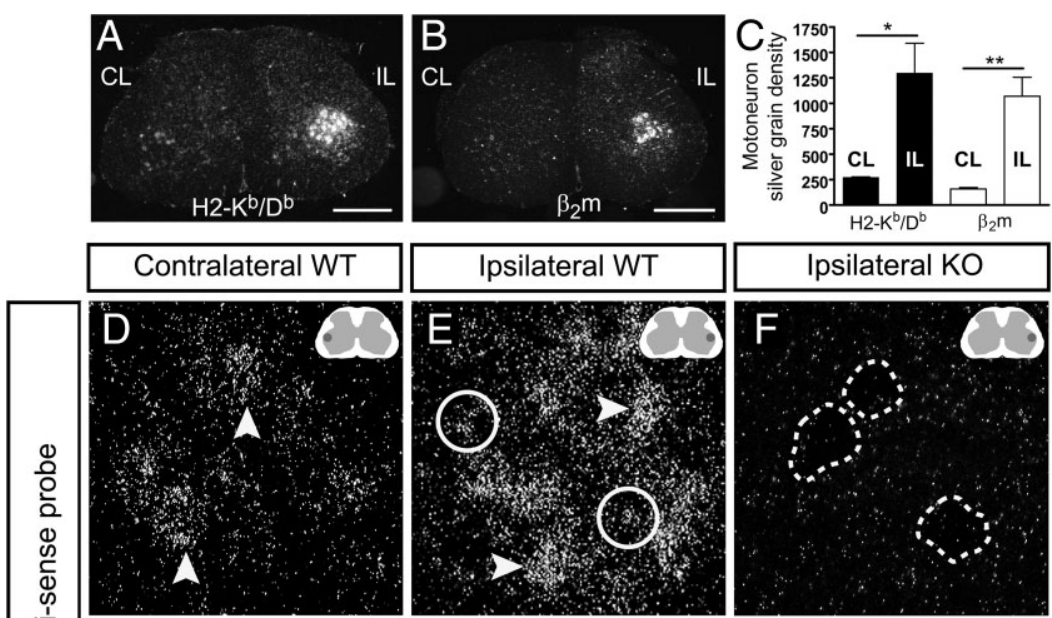

\section{.}

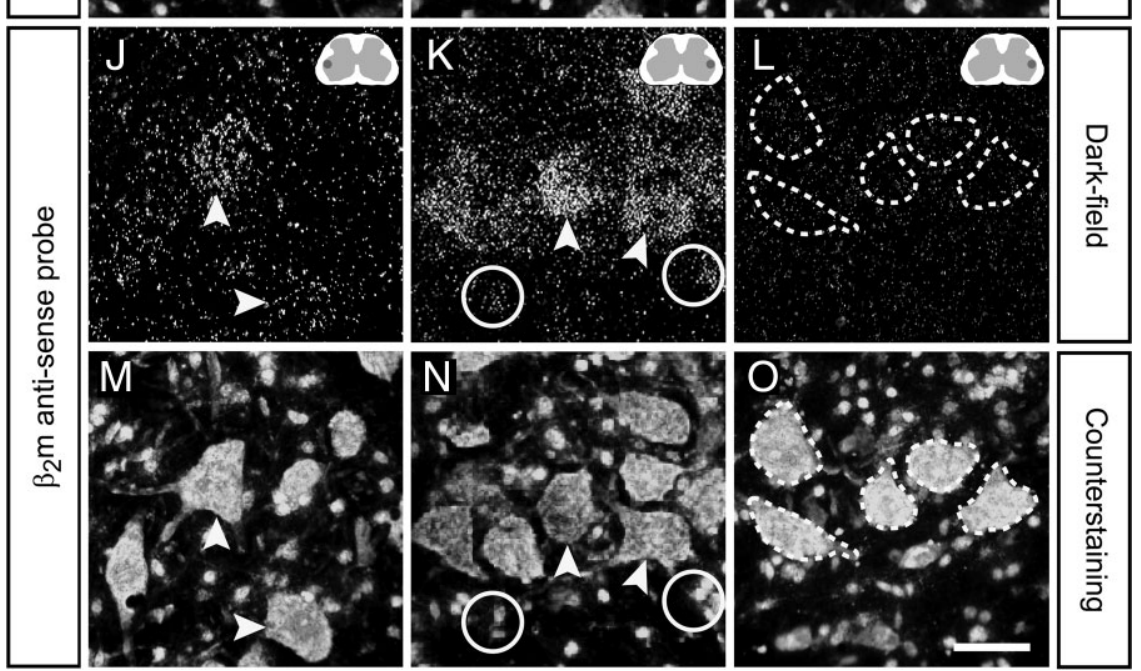

Figure 1. Expression of MHC class la and $\beta_{2}$ m mRNAs in the spinal cord. $\boldsymbol{A}, \boldsymbol{B}$, Low-magnification dark-field micrographs showing in situ hybridization with $\mathrm{H} 2-K^{\mathrm{b}} / \mathrm{D}^{\mathrm{b}}$ and $\beta_{2} \mathrm{~m}$ mRNA probes on spinal cord sections 1 week after SNT. Note the strong mRNA signal for both probes in the ipsilateral (IL) ventral horn compared with the contralateral (CL) side. Scale bars, $500 \mu \mathrm{m}$. The darker field in the inset schematic figure denotes the dorsolateral ventral horn were the image is captured. $\boldsymbol{C}$, The upregulation of mRNAs was estimated by comparing the silver grain density over axotomized motoneurons with that of intact motoneurons. Bars show mean \pm SEM. ${ }^{*} p<0.05 ;{ }^{* *} p<0.01$. $\boldsymbol{D}, \boldsymbol{E}$ and $\boldsymbol{J}, \boldsymbol{K}$, Dark-field micrographs in higher magnification revealed the cellular expression of $\mathrm{H} 2-\mathrm{K}^{\mathrm{b}} / \mathrm{D}^{\mathrm{b}}$ and $\beta_{2} \mathrm{~m}$ mRNAs in contralateral and ipsilateral ventral horns from WT mice. Scale bar, $50 \mu \mathrm{m} . \boldsymbol{F}, \boldsymbol{L}$ and $\boldsymbol{I}$, 0 , Spinal cord sections from operated $K^{b-1-} D^{b-1-}$ and $\beta_{2} m^{-1-}$ mice were used as negative controls (KO) for the mRNA probes; dashed lines mark the position of injured motoneurons. $\boldsymbol{G}, \boldsymbol{H}$, Bis-benzimide counterstaining was used to identify large neurons (arrowhead) and glial cells (circles).

(Fig. 3 B, C). H2-D ${ }^{\mathrm{b}}$-IR was also observed in the extremes of the stump, indicating expression in growth cones (Fig. 3C).

We next studied $\mathrm{H} 2-\mathrm{D}^{\mathrm{b}}$-IR at neuromuscular synapses, which we will refer to as NMJs, in the GCM. The presynaptic motor terminals were stained with either syph or VAChT, and the postsynaptic AChR clusters were visualized with $\alpha$-btx. H2$\mathrm{D}^{\mathrm{b}}$-IR was observed at the NMJ in both the intact and reinnervated GCM (Fig. 4A). The staining appeared to be somewhat more intense in the reinnervated muscles compared with the uninjured ones. In resemblance to the staining pattern in the 


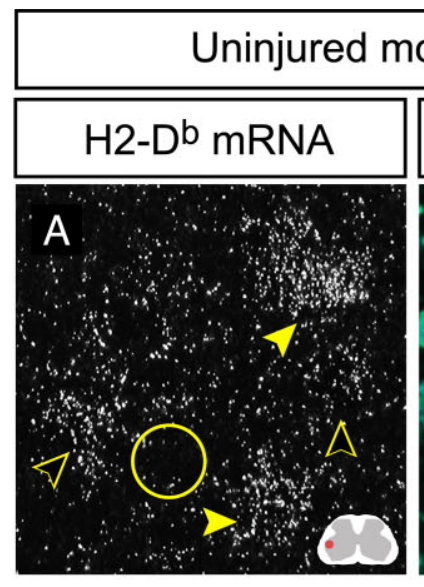

\section{otoneurons}
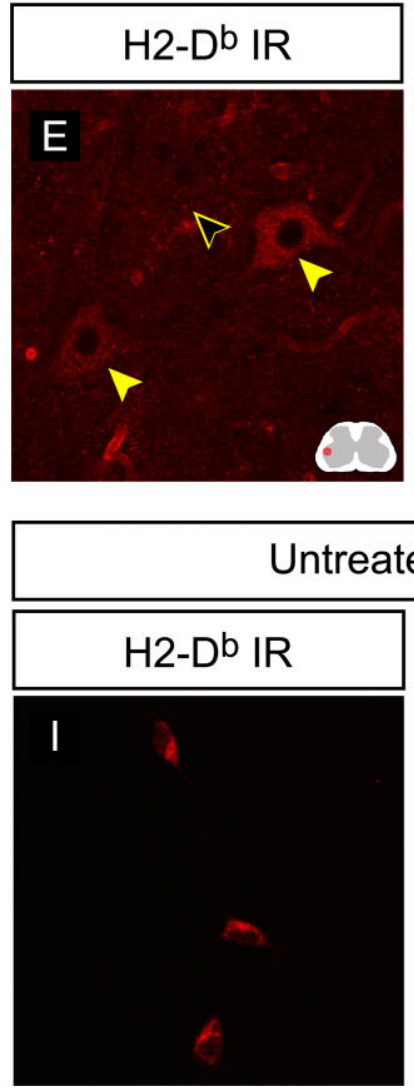
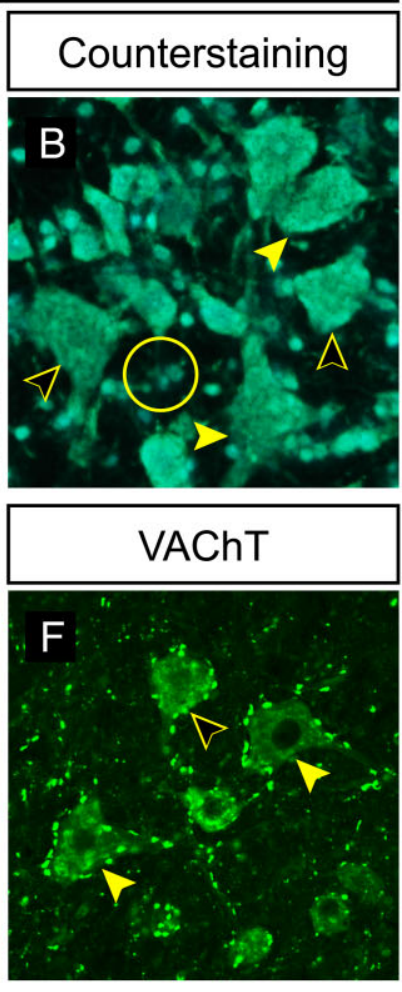

MN1

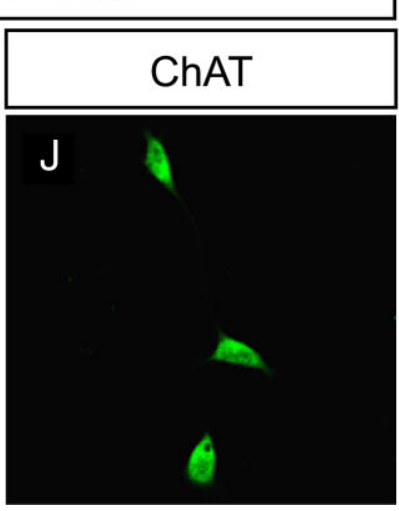

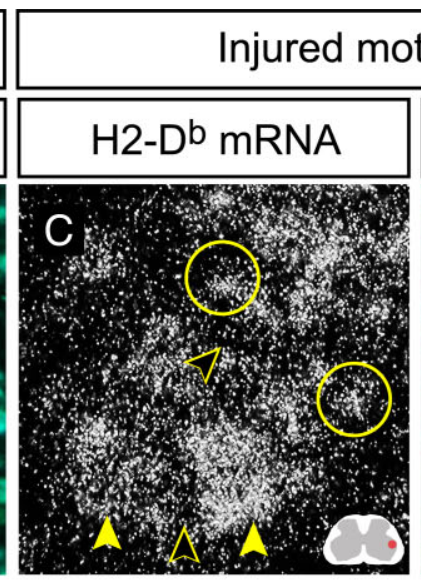
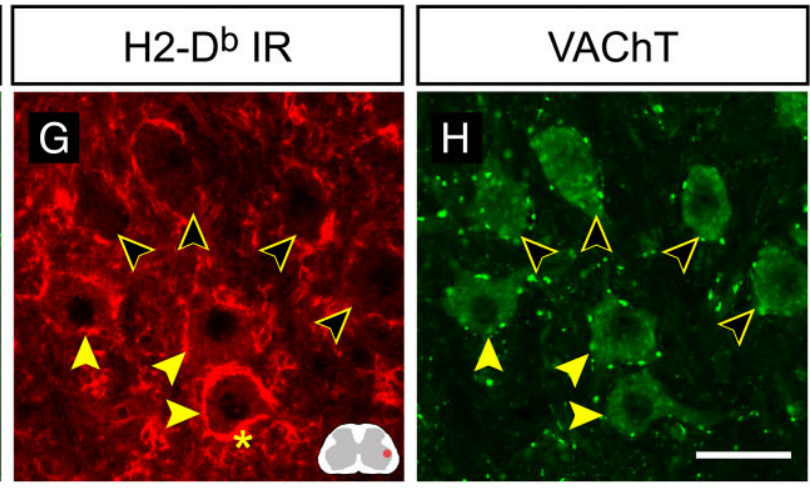

Figure 2. $\quad H 2-D^{b}$ expression in spinal motoneurons and the $M N-1$ cell line. $A-D$, Dark-field and counterstaining micrographs showing in situ hybridization with the $H 2-K^{b} / D^{b}$ probe on spinal cord sections from normal and operated $K^{b-1-}$ mice at 1 week after SNT. Filled arrowheads indicate motoneurons with high mRNA expression, open arrowheads indicate motoneurons with moderate to low expression, and circles mark surrounding glia. Scale bar, $50 \mu \mathrm{m}$. The red field in the inset schematic figure denotes the dorsolateral ventral horn were the image is captured. $\boldsymbol{E}-\boldsymbol{H}$, Confocal micrographs (maximum projections) showing coexistence of $\mathrm{H} 2-\mathrm{D}^{\mathrm{b}}$ and VAChT-IR in uninjured WT animals and operated WT animals at 1 week after SNT. Filled arrowheads indicate motoneurons with $H 2-D^{b}$-IR, open arrowheads indicate motoneurons that are negative, and the asterisk marks H2-D ${ }^{b}$-IR in surrounding microglia. Scale bar, $50 \mu m$. $I-L$, Confocal micrographs showing $H 2-D^{b}$ and ChAT-IR in untreated and IFN- $\gamma$-treated cultures of the MN- 1 cell line. Filled arrowheads mark H2-D ${ }^{\mathrm{b}}$-IR in a growth cone-like process. Scale bar, $50 \mu \mathrm{m}$.

spinal cord and sciatic nerve, a subpopulation of NMJs, usually clustered together, showed $\mathrm{H} 2-\mathrm{D}^{\mathrm{b}}-\mathrm{IR}$, and the intensity varied between individual NMJs. At $10 \mathrm{~d}$ after SNC, the presynaptic terminals were degenerated and no $\mathrm{H} 2-\mathrm{D}^{\mathrm{b}}$-IR was detected at the remaining AChR clusters (our unpublished data). At 3 and 4 weeks after SNC, presynaptic terminals had reinnervated the muscle fibers, and the NMJs showed H2-D ${ }^{\mathrm{b}}$-IR (Fig. 4A). Confocal stacks revealed that the $\mathrm{H} 2-\mathrm{D}^{\mathrm{b}}$-IR appeared to be present at the presynaptic side of the NMJ, shown with triple labeling for $\alpha$-btx, H2-D ${ }^{\mathrm{b}}$, and syph (Fig. $4 B$ ) or VAChT (our unpublished data). By studying three-dimensional reconstructions of triple- labeled NMJs, we found strong indications that, at the $\mathrm{H} 2-\mathrm{D}^{\mathrm{b}}$ positive elements were present in the presynaptic terminal itself, but we also found some overlap suggesting simultaneous expression in SCs, which has been reported previously (Tsuyuki et al., 1998).

Abnormal muscle innervation in the absence of classical MHC class I

Because we detected $\mathrm{H} 2-\mathrm{D}^{\mathrm{b}}$-IR in presynaptic motor terminals at NMJs, we next studied whether the absence of MHC class Ia molecules affected muscle innervation and formation of synapses 


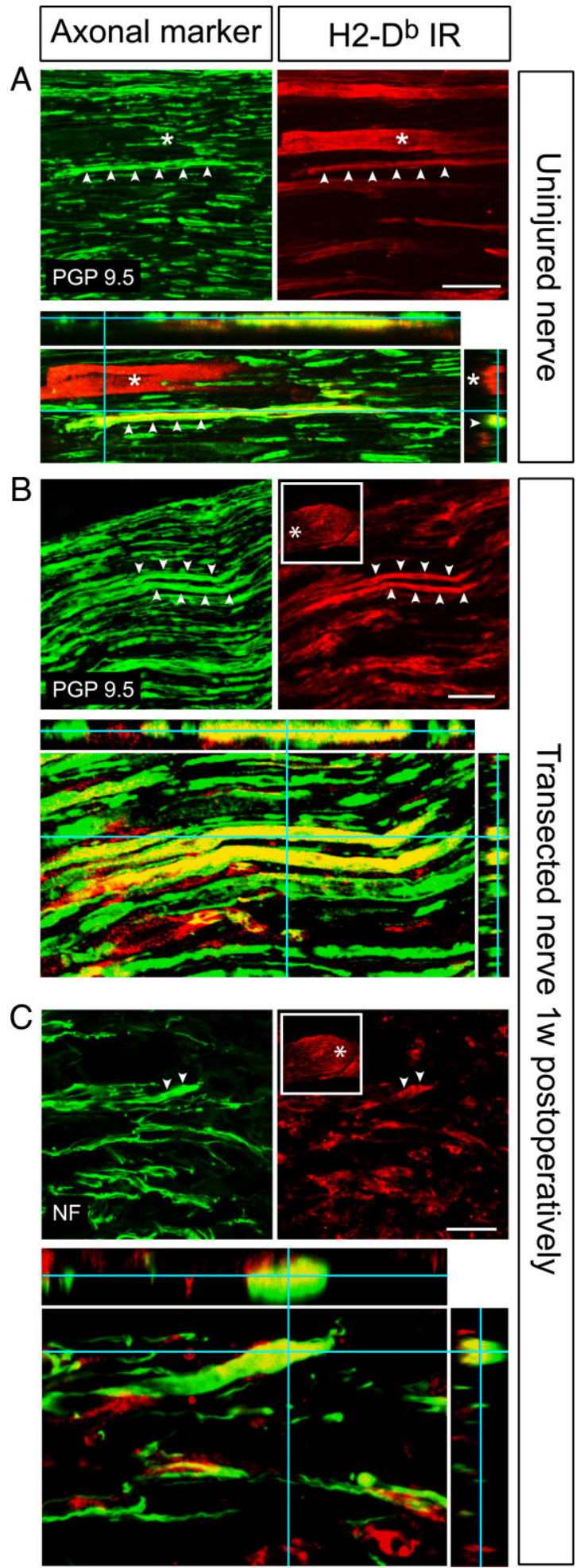

Figure 3. Axonal expression of $\mathrm{H} 2-D^{b}$ molecules in the intact and transected nerve. $A$, Confocal micrographs (maximum projections) from the uninjured sciatic nerve showing a $\mathrm{H}_{2}-\mathrm{D}^{\mathrm{b}}$ positive axon in red, which is colocalized with the axonal marker PGP9.5 in green (arrowheads). $H 2-D^{b}-I R$ is also present in a blood vessel (asterisk). Colocalization is shown in yellow in the orthogonal projection (bottom). Scale bars, $50 \mu \mathrm{m}$. B. Confocal micrographs (maximum projections) showing $\mathrm{H} 2-\mathrm{D}^{\mathrm{b}}-\mathrm{IR}$ (red) and PGP9.5 (green) labeling in the proximal stump of the transected sciatic nerve at $7 \mathrm{dpo}$. Asterisks mark two axons that are positive for both markers. The framed inset shows the localization in the nerve stump from where the confocal image is taken (asterisk). Colocalization is shown in yellow in the orthogonal projection (bottom). C, Confocal micrographs (maximum projections) showing H2- ${ }^{\mathrm{b}}-\mathrm{IR}$ (red) and NF (green) labeling in the end of the sciatic nerve stump (asterisk in framed inset) at $7 \mathrm{dpo}$. Note the $\mathrm{H}_{2}-\mathrm{D}^{\mathrm{b}}-\mathrm{IR}$ in in $K^{b-/-} D^{b-/-}$ mice. In addition, we compared muscle fiber cross-sectional area and distribution in WT and $K^{b-/-} D^{b-/-}$ mice to detect possible abnormalities in muscle architecture or signs of atrophy.

The muscle fiber architecture, the mean muscle fiber area, and the muscle fiber size frequency were similar in the two strains (Fig. 5B). More or less all $\alpha$-btx-positive AChR clusters appeared to be positive also for syph in both strains for all time points analyzed, indicating that all AChR clusters were innervated. We thus used AChR clusters as a marker for NMJs in our analysis. The NMJs were organized in sinus-shaped synapse bands across the width, length, and depth of the hindlimb muscles that were grossly similar in both strains (Fig. $5 A$ ). However, the synaptic bands appeared to be denser in intact hindlimb muscles from $K^{b-1-} D^{b-1-}$ mice, which was confirmed by analyzing the density of AChR clusters. Unoperated $K^{b-1-} D^{b-1-}$ mice displayed a $27 \%$ higher density of AChR clusters $\left(6.9 \pm 0.3\right.$ clusters $\left./ \mathrm{mm}^{2}\right)$ in the hindlimb muscles compared with WT mice (5.5 \pm 0.4 clusters/ $\mathrm{mm}^{2}$ ) (Fig. 5C).

There was a certain degree of heterogeneity in synaptic band structure between hindlimb muscles from individual $K^{b-/} D^{b-/-}$ animals. As described above, a majority of $\mathrm{K}^{b-/-} D^{b-/-}$ mice had a normal synaptic band structure but a higher density of AChR clusters. However, certain $K^{b-/-} D^{b-/-}$ animals also displayed localized disruptions of the synaptic band structure (Fig. $5 A$ ).

$K^{b-1-} D^{b-1-}$ mice have a selective immunodeficiency caused by a lack of MHC class I-restricted immune function, resulting in a decreased function of $\mathrm{CD}^{+}$(cytotoxic) T-cells. Therefore, to rule out that the structural changes seen in muscles from $\mathrm{K}^{\mathrm{b-}-\text { - }}$ $D^{b-/-}$ were secondary to this impaired immune function, AChR cluster density and synaptic band pattern were analyzed in uninjured hindlimb muscles from $R A G 1^{-/-}$mice (Fig. 5C). These mice lack mature $\mathrm{T}$ - and $\mathrm{B}$-cells as a result of defective recombination of receptor genes but express MHC molecules in a normal manner. No significant difference was seen between $R A G 1^{-/-}$ mice and WT mice regarding density of AChR cluster or synaptic band morphology (our unpublished data). We thus conclude that the muscle phenotype seen in $K^{b-/-} D^{b-/-}$ mice cannot be explained by $\mathrm{T}$-cell immune deficiency.

\section{Structural abnormalities in muscle innervation is a general property in MHC class I-deficient mice}

To confirm that the changes in synaptic band structure in $K^{b-/-} D^{b-/-}$ mice was not an isolated phenomenon restricted to hindlimb muscles, we further studied synaptic bands in the diaphragm, which allowed a whole-mount imaging approach. The diaphragm has a simpler muscle fiber architecture than the hindlimb muscles, and the NMJs are therefore concentrated in continuous centralized band following the course of the phrenic nerve along the diaphragm (Fig. 6A). Using this experimental approach, we scanned through the depth of the diaphragm in a series of $z$-stacks and were then able to put the maximum projections together into montages, thereby reconstructing the synaptic bands (Fig. 6A, B). When studying these montages, we observed a consistently pronounced disturbance in synaptic band structure in $K^{b-1-} D^{b-/-}$ mice (11 of 14 animals), with a specific localization to the right hemidiaphragm, near the entry zone for the phrenic nerve. Such changes were absent in WT mice (0 of 10).

\section{$\leftarrow$}

NF-positive outgrowing axon tips (asterisks). Colocalization is shown in yellow in the orthogonal projection (bottom). 


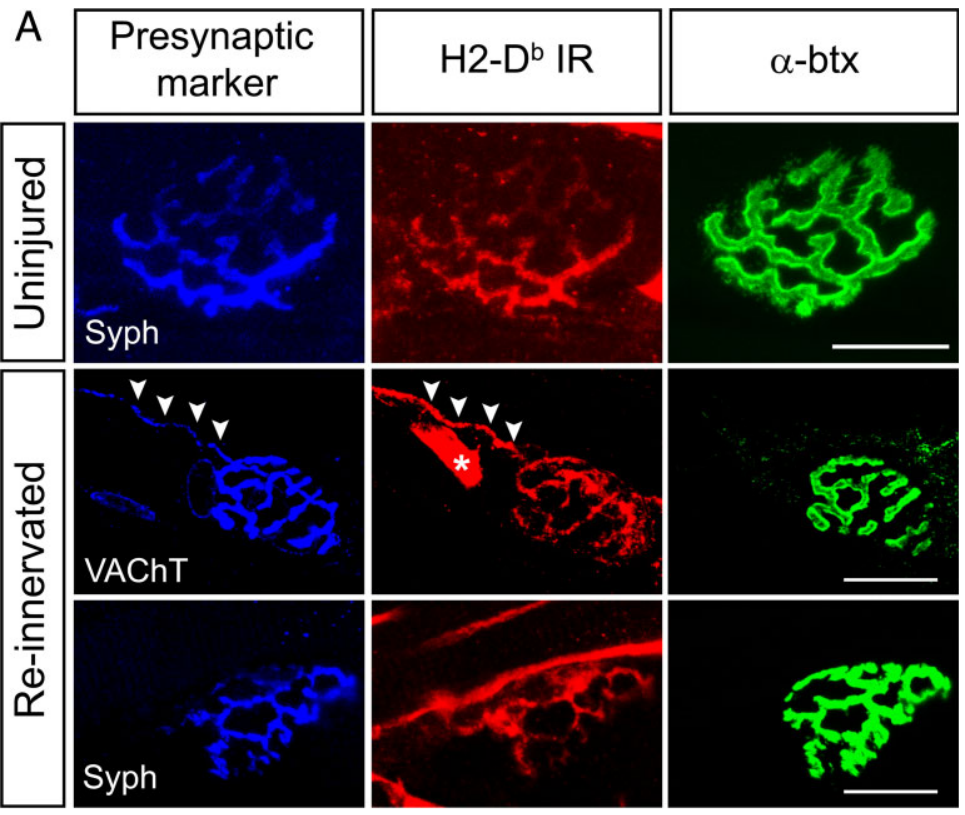

B
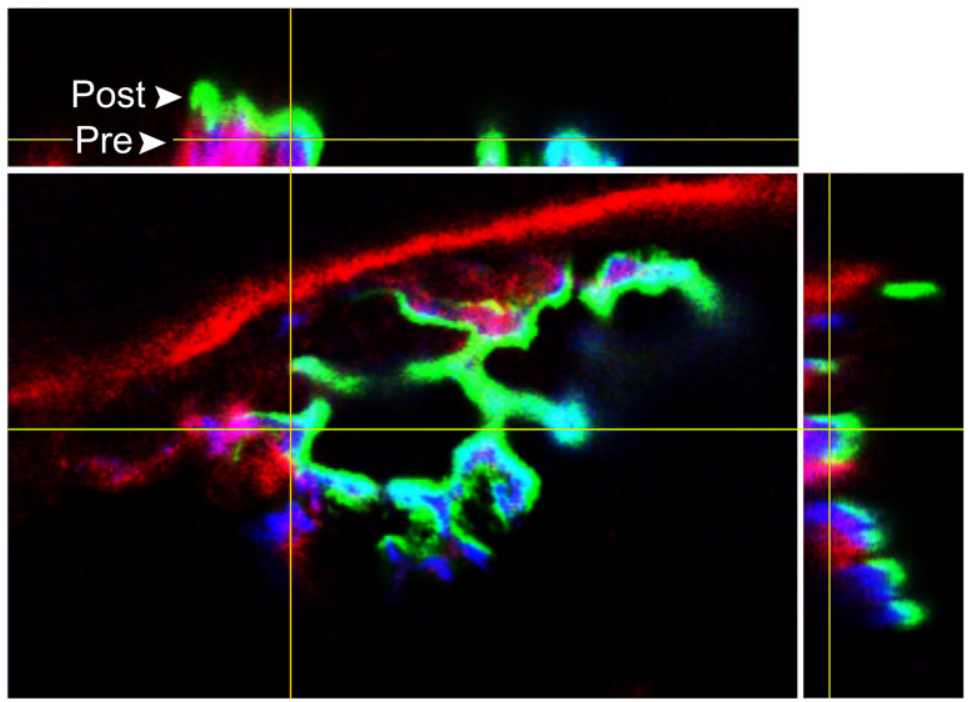

Figure 4. $\quad H 2-D^{b}$ molecules are expressed at the NMJ. $\boldsymbol{A}$, Confocal micrographs (maximum projections) of normal and reinner-

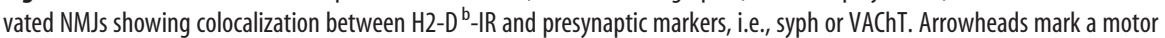
axon terminal, which displays both VAChT and H2-D ${ }^{b}$-IR. Asterisk indicates a vessel with $\mathrm{H}_{2}-\mathrm{D}^{\mathrm{b}}$-IR. Scale bars, $20 \mu \mathrm{m}$. B, An orthogonal projection of a $z$-stack $\left(0.1 \mu \mathrm{m}\right.$ section interval) showing a triple-labeled NMJ. H2-D ${ }^{\mathrm{b}}$ in red is presynaptically colocalized (pink) with syph in blue. Postsynaptic AChR clusters are shown in green. Arrowheads indicate the presynaptic and postsynaptic layers of the NMJ.

Like in the hindlimb muscles, the density of NMJs appeared to be higher, particularly in right hemidiaphragm. This observation was confirmed by counting the mean number of AChR clusters per millimeter synapse band length. In the right hemidaphragm, the number of clusters per millimeter was $\sim 30 \%$ higher $(p<$ $0.01)$ in $K^{b-/-} D^{b-/-}(131.9 \pm 4.2 ; n=4)$ compared with WT mice $(100.8 \pm 2.0 ; n=3)$.

Because synaptic elimination and refinement is a well known feature of early postnatal development, we further studied the synaptic band structure in postnatal diaphragms from WT and $K^{b-/-} D^{b-1-}$ mice at various time points after birth $(n=3$ per strain and time point). In addition, a transient right-left asymmetry in the normal developmental innervation of the diaphragm has been reported (Laskowski et al., 1991). At the day of birth [post- natal day $0(\mathrm{P} 0)]$, WT and $K^{b-/-} D^{b-/-}$ mice displayed similar misalignments in the right hemidiaphragm (Fig. $6 B$ ). In the WT mice, this pattern was gradually changed at P4 and P8 into the normal adult pattern seen at P42, whereas $K^{b-/-} D^{b-/-}$ mice retained these misalignments into adulthood (Fig. 6B).

\section{MHC class I-deficient mice exhibit abnormal dynamic changes in NMJ density during muscle reinnervation} To study formation of NMJs in the adult muscle, we studied AChR cluster density in the hindlimbs at $14,20,30$, and $45 \mathrm{dpo}$ after SNC with subsequent reinnervation. At 14 dpo, both groups displayed the highest density measured, and there was no difference between WT and $K^{b-/-} D^{b-/-}$ mice. At 20 dpo, there was a pronounced decrease in AChR cluster density in the WT mice, in contrast to the $\mathrm{K}^{b-/-} \mathrm{D}^{b-/-}$ mice, which showed a considerably smaller reduction (Fig. 5C). At 30 and 45 dpo, both groups continued to decrease in density, but a statistically significant $(p<0.01)$ difference of $\sim 40 \%$ remained between WT and $K^{b-/-} D^{b-/-}$ mice (Fig. 5C).

\section{Muscle fibers from adult $\mathrm{K}^{b-/-} D^{b-/-}$ mice can express more than one AChR cluster}

Because we detected a higher density of AChR clusters in uninjured muscles from adult $K^{b-1-} D^{b-/-}$ mice without any differences in muscle fiber size or composition, we explored the possibility that single muscle fibers express more than one AChR cluster. We therefore examined muscle fiber bundles consisting of 2-10 fibers from the lateral GCM stained with fluorescent $\alpha$-btx. The fibers were evaluated blindly with regard to genotype. Three-dimensional reconstructions were created from confocal $z$-stacks to study the location of individual AChRs. We used the curvature of the AChR clusters and the invagination in the muscle fiber membranes to determine on which fibers nearby clusters were situated. In all WT fibers, we detected a single cluster per muscle fiber. In $K^{b-1-} D^{b-1-}$ fibers, however, we observed examples of individual muscle fibers expressing at least two AChR clusters, which were placed rather close to each other (Fig. 5D) or with a clear distance in between (supplemental Fig. S5, available at www.jneurosci.org as supplemental material). These abnormal fibers were intermingled with normal muscle fibers.

MHC class I-deficient mice have a decreased covering of TSCs at the NMJ

Because we detected a disturbance in the organization and density of NMJs in $K^{b-/-} D^{b-1-}$ mice, we further studied individual NMJs to detect possible morphological abnormalities. To do so, 

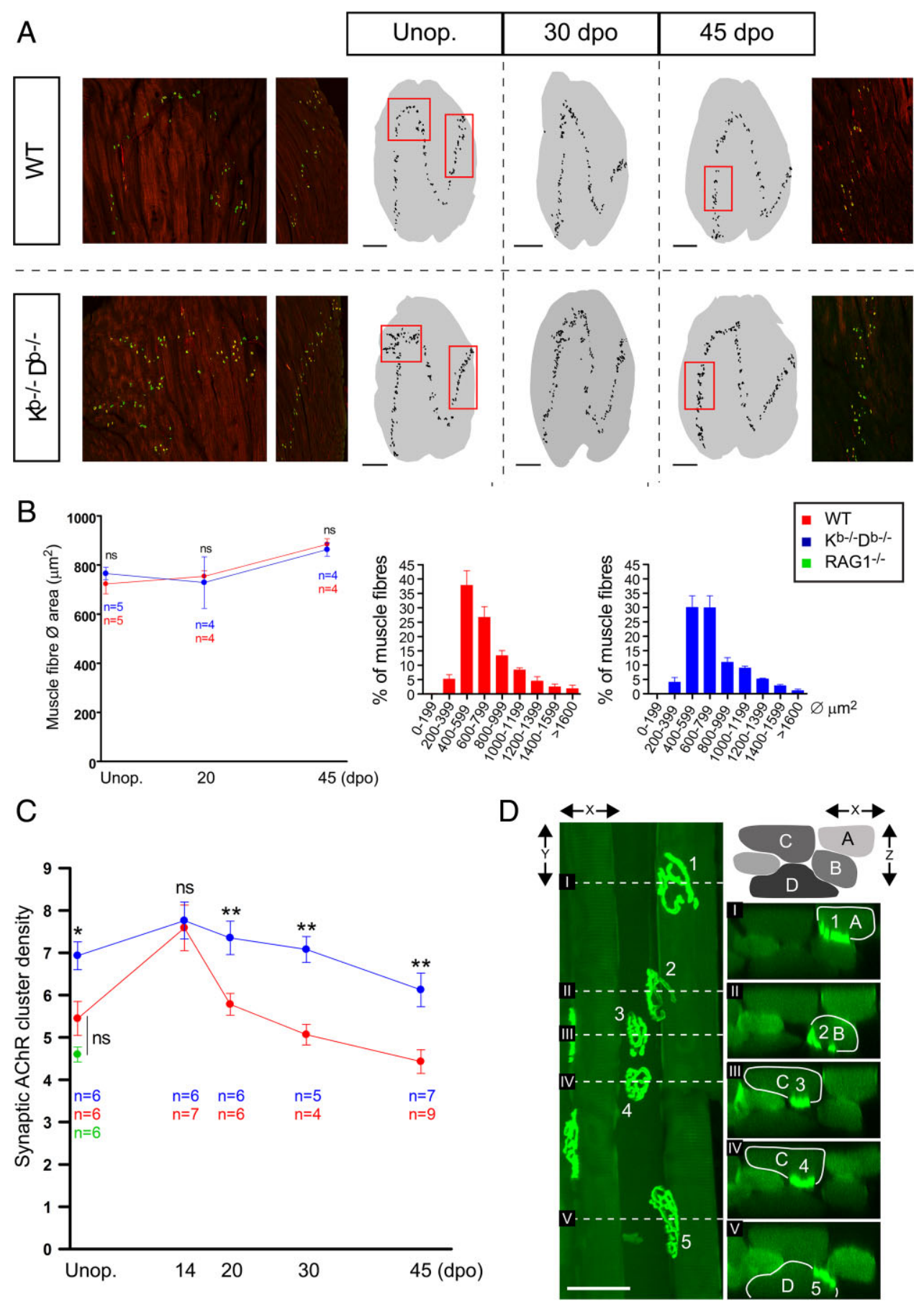

Figure 5. MHC class la-deficient mice display a higher density of NMJs in normal and reinnervated muscles. $A$, Confocal micrographs from WT and $K^{b-/-} D^{b-/-}$ mice showing $\alpha$-btx (green) and syph (red) costaining in the normal (left) and reinnervated lateral GCM. Traced staining patterns from representative muscle montages are shown as black pixels on gray background representing the muscle section contour. The black dots represent individual AChR clusters. Red rectangles show the areas corresponding to the confocal micrographs. Scale bars, $1 \mathrm{~mm}$. B, The average muscle fiber area in the unoperated (Unop.) and reinnervated medial GCM at 20 and $45 \mathrm{dpo}$, presented as mean \pm SEM. To the right, muscle fiber cross-sectional area distribution in unoperated GCM; bars show the frequency of muscle fibers within a size interval. $C$, A time course plot showing the changes in synaptic AChRs density in the uninjured and reinnervated lateral $G C M$ from WT, $K^{b-\prime-} D^{b-\prime-}$, and uninjured $B 6 . R A G 1^{-1-}$ mice; bars show mean \pm SEM. ns, Not statistically significant; ${ }^{*} p<0.05 ;{ }^{* *} p<0.01$. D, A confocal maximum projection in $x-y$ showing a bundle of muscle fibers from a $K^{b-1-} D^{b-/-}$ animal stained with $\alpha$-btx. The dashed lines denoted with roman numerals correspond to the sectional planes of the $x-z$ projections shown to the right. The muscle fibers are denoted by capital letters $(\boldsymbol{A}-\boldsymbol{D})$, and the AChR clusters are denoted by numbers $(1-5)$. Note the two distinct clusters $(3,4)$ present on fiber C. Scale bar, $50 \mu \mathrm{m}$.

we first studied general NMJ morphology and synaptic AChR cluster size. TSCs have been shown to be involved in NMJ plasticity (Love and Thompson, 1998; Sanes and Lichtman, 1999; Reddy et al., 2003; Bishop et al., 2004; Song et al., 2006; Feng and Ko, 2007). We therefore studied the TSC covering of individual NMJs (supplemental Fig. S3, available at www.jneurosci.org as supplemental material) in the hindlimb muscles. The postsynaptic AChR clusters appeared to be innervated by one axon each, and the alignment between presynaptic and postsynaptic elements was normal in WT and $K^{b-1-} D^{b-1-}$ mice (our unpublished data). We detected a slightly smaller AChR cluster area in $K^{b-1-} D^{b-1-}$ mice compared with WT, which was sta- 
A

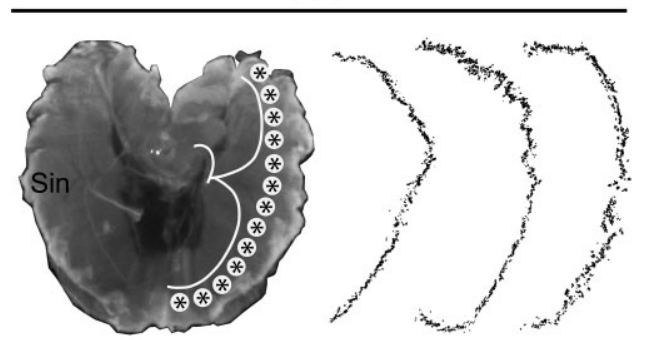

$\mathrm{K}^{\mathrm{b}-/-\mathrm{D}} \mathrm{b}-/-$

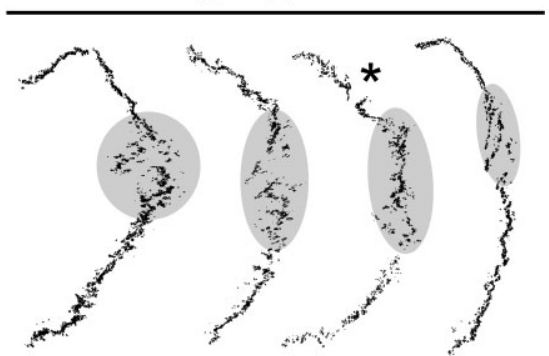

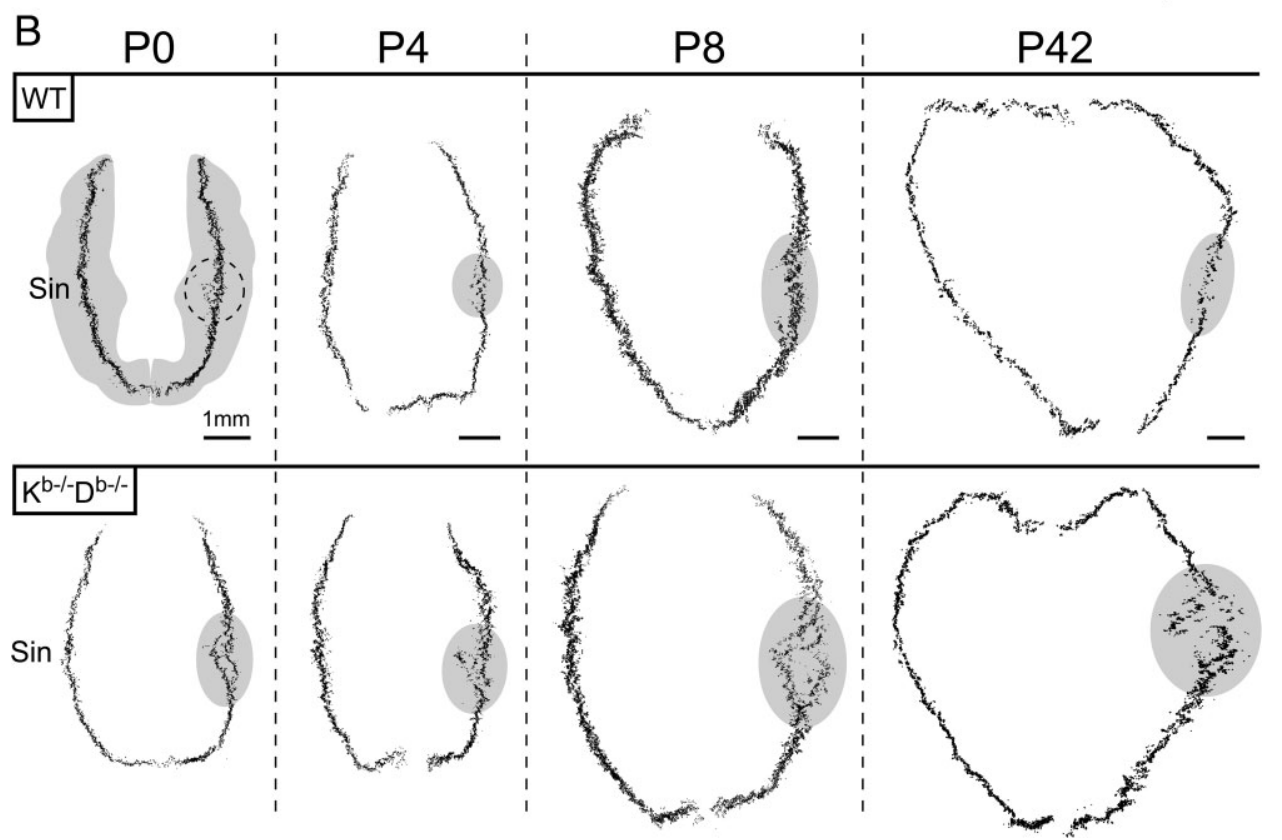

Figure 6. Abnormal innervation of the diaphragm in MHC class la-deficient mice. $\boldsymbol{A}$, To the left, a photograph of the diaphragm from a WT mouse, which serves as a reference for the shape of the synaptic bands. The location for the phrenic nerve is marked with a white line, and the placement of the synaptic bands are represented by asterisks. Sin, Left side. Traced staining patterns from representative whole-mount montages of the NMJ distribution are displayed as black pixels. Disrupted synaptic bands are indicated with gray fields. The asterisk in the montages from $K^{b-} /-D^{b-}-{ }^{-}$ mice marks an artifactual disruption of the band structure that is the result of a dissection damage to the diaphragm. $\boldsymbol{B}$, Reconstruction of the synaptic bands from whole-mount preparation at different postnatal stages from birth up to the adult stage. Top left part (WT, P0) shows the location of the synaptic band on a gray contour of the costal diaphragm in gray, and a dashed line marks a misalignment on the right side. Misalignments or the area of interest is highlighted by gray fields in the other reconstructions.

tistically significant in normal but not in reinnervated synapses (Fig. 7B).

When analyzing the number of TSCs at individual intact NMJs, we found that WT NMJs were covered by $2.5 \pm 0.2$ TSCs (Fig. $7 B$ ). Because there is a positive correlation between the number of TSCs and the size of the AChR cluster, we also calculated the ratio between the number of TSC/NMJ and the AChR cluster area. In WT muscles, there was an average covering of $192.7 \pm 9.7 \mu \mathrm{m}^{2}$ AChR cluster area/TSC (Fig. $7 B$ ). This can be compared with the significantly lower number of TSCs $(1.8 \pm$ 0.1 TSCs/NMJ) and a larger AChR cluster area per TSC $\left(236.1 \pm 14.1 \mu \mathrm{m}^{2} /\right.$ TSC) at $K^{b-1-} D^{b-1-}$ NMJs (Fig. $7 B$ ). In resemblance to the changes in AChR cluster density after reinnervation, we did not detect any difference in number or covering of TSCs between WT and $K^{b-/-} D^{b-/-}$ at 14 dpo (Fig. $7 B)$. After $14 \mathrm{dpo}$, the WT group exhibited a distinct increase in TSC number, whereas the $K^{b-1-} D^{b-1-}$ remained virtually unchanged at later time points (Fig. $7 B$ ).

\section{Expression of MHC class I receptors in dissociated SCs and in the sciatic nerve}

The most well known receptor for MHC class I is the CD3 associated T-cell receptor (TCR), and recent publications indicate that PIRs and members of the Ly49 receptor family act as receptors for neuronally expressed MHC class I molecules (Syken et al., 2006; Zohar et al., 2008). We thus found it important to search for expression of such receptors in the nerve and muscle. Because we found a lower number of TSCs/NMJ in intact and even more so in reinnervated muscles in MHC class I-deficient mice, we hypothesized that the muscle phenotype could be caused by a disturbed MHC class I-mediated interaction involving SCs. This led us to investigate whether SCs expressed MHC class I receptors that could interact with presynaptic MHC class I molecules expressed by motor axons. SCs were therefore acutely dissociated from the sciatic nerves of 4-d-old WT mice and then analyzed with FACS. Using this technique, we found a subpopulation of SCs that was positive for PIRs, in particular PIR-B, and the P75 neurotrophin receptor, which was used as a SC marker (Fig. 7E). P75 has been shown to be expressed and upregulated by SCs in the peripheral nerve during nerve injury (Hirata et al., 2001). Although the distribution of P75 expression in dissociated SCs is unknown, we could use this marker to distinguish the SCs from other cell types present in the nerve. In contrast, P75-positive SCs were negative for members of the Ly49 receptor family (supplemental Fig. S4, available at www.jneurosci.org as supplemental material). 

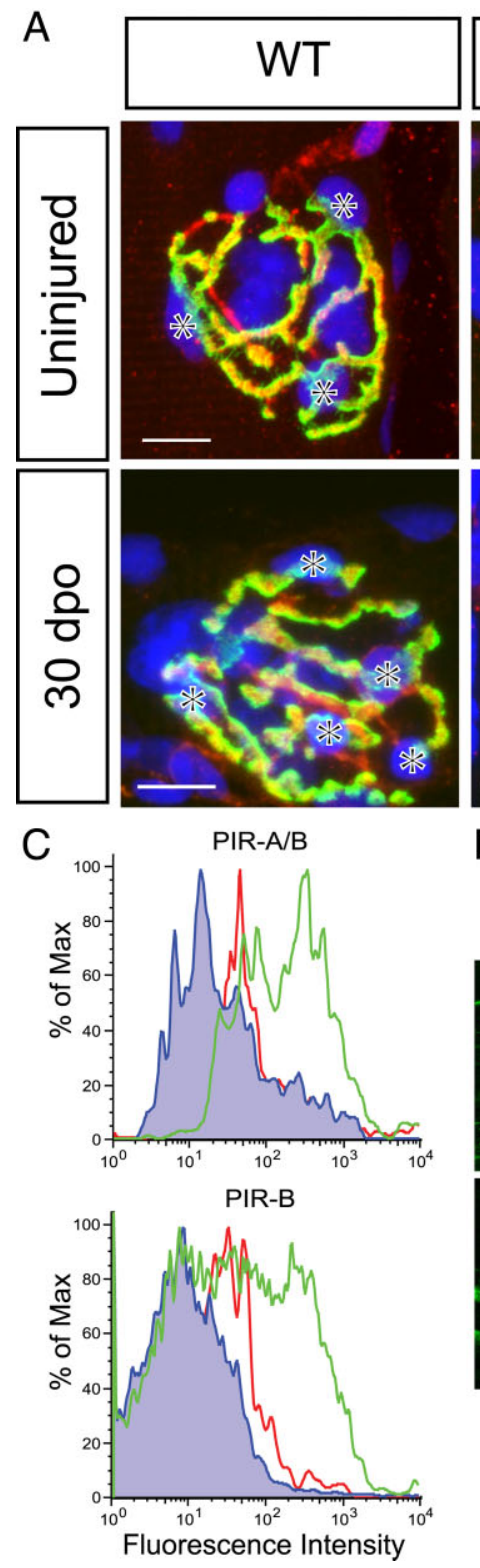
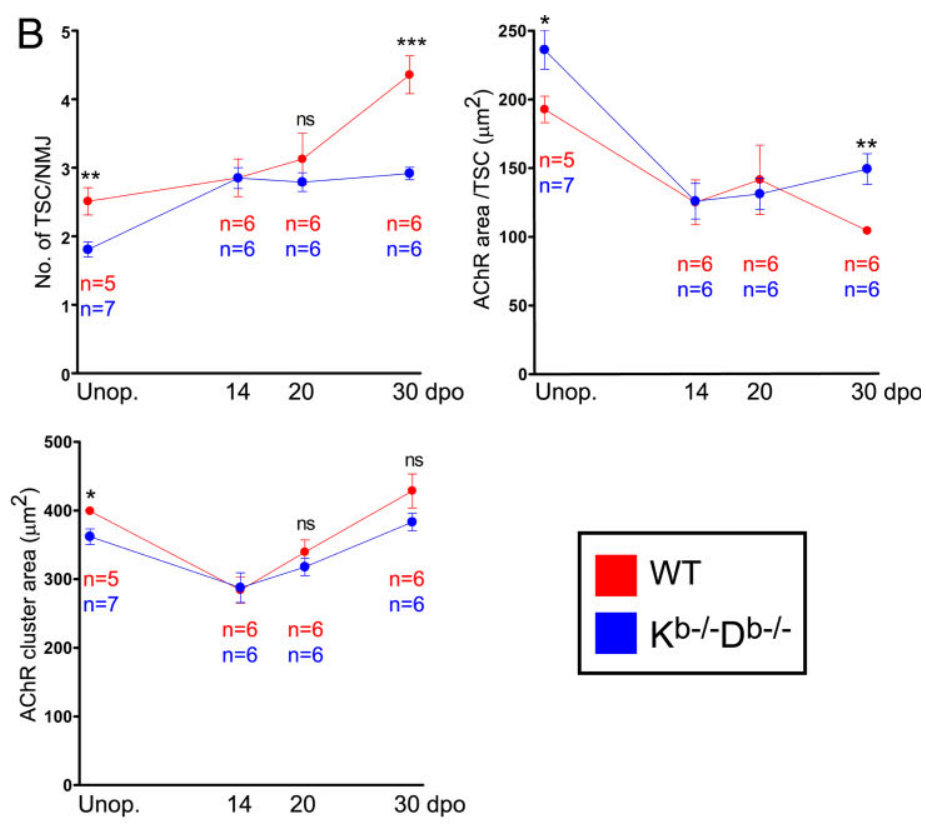

$\mathrm{D}$
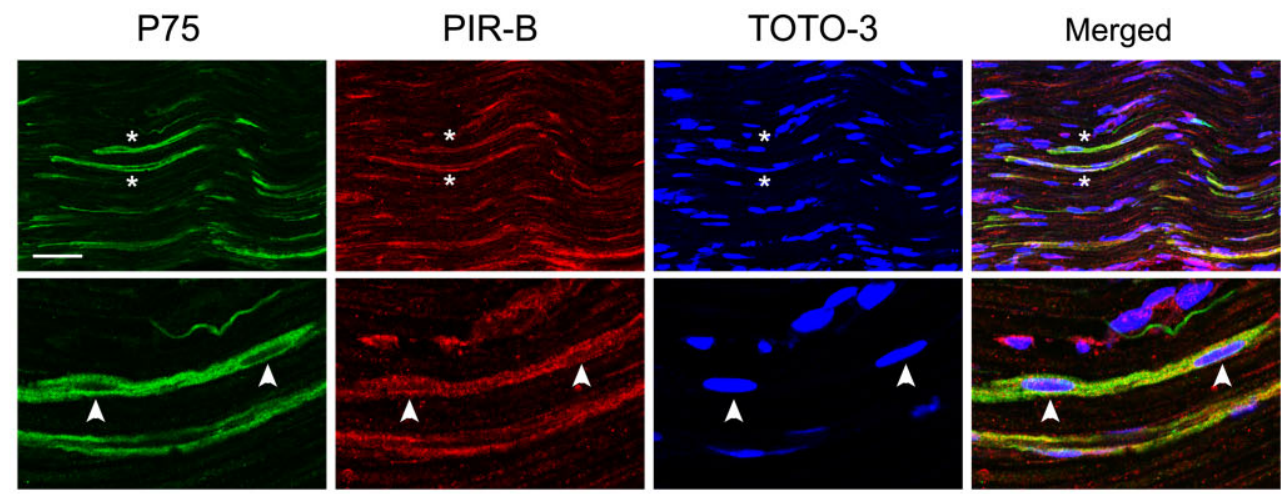

Figure 7. Fewer TSCs stabilize NMJs in MHC class la-deficient mice, and they proliferate less during reinnervation. $\boldsymbol{A}$, Confocal micrographs of uninjured and reinnervated ( $30 \mathrm{dpo}$ ) WT and $K^{b-/-} D^{b-/-}$ NMJs triple stained with $\alpha$-btx (postsynaptic, green), S100 (Schwann cell, red), and TOTO-3 (nuclei, blue). Asterisks indicate TSCs at representative NMJs. Scale bars, $10 \mu \mathrm{m} . \boldsymbol{B}$, Time course plot showing the mean \pm SEM values for the number of TSCS/NMJ, the TSC covering (AChR cluster area/number of TSCS) at individual NMJs, and the mean AChR cluster area in the lateral GCM from unoperated (Unop) animals and during reinnervation after nerve crush. ns, Not statistically significant; ${ }^{*} p<0.05 ;{ }^{* *} p<0.01 ;{ }^{* * *} p<0.001$. C, Single-cell suspensions of enriched Schwann cells were prepared and stained with antibodies for indirect immunofluorescence detecting P75 (to identify Schwann cells) and PIR-A/B and PIR-B. The histograms depict cells in the P75 ${ }^{+}$gate, incubated without any additional antibody (blue), with a rat anti-PIR-A/B and PIR-B antibody in combination with a secondary FITC-conjugated anti-rat Ig (green) or with a secondary FITCconjugated antibody alone as negative control (red). D, Confocal micrographs showing a triple staining with P75 (green), PIR-B (red), and T0T0-3 (blue) in intact sciatic nerve. Asterisks denote two colabeled axon profiles. The arrowheads in the magnified pictures show two nuclei, most likely belonging to Schwann cells. Scale bar, $50 \mu \mathrm{m}$.

Using the same PIR-B antibody for immunohistochemistry, we observed a consistent staining of $\mathrm{P} 5^{+}$elements in the sciatic nerve (Fig. 7D), indicating also an expression of PIR-B in SCs in vivo. However, we failed to detect immunoreactivity for PIR-B in TSCs at the NMJ, which was also the case for TCR, CD3, or the DAP12 adaptor molecule associated to activating Ly49 receptors (our unpublished data).

\section{Delayed recovery of motor function after nerve crush in the} absence of MHC class Ia molecules

It has been shown that the density of NMJs at the histological level reflects the functional recovery after nerve crush (Verdu and
Navarro, 1997). To study the effect of MHC class I deficiency on the muscle recovery after nerve lesion, WT mice were compared with B6. $K^{b-1-} D^{b-1-}$ mice during $45 \mathrm{~d}$ after sciatic nerve crush with regard to recovery of motor function in the hindlimb muscles, assessed by grip ability. The animals were trained at several testing sessions before the operations, and no difference in the ability to grip a metal rod was seen in unoperated WT $(n=10)$ or $K^{b-1-} D^{b-1-}(n=7)$ animals (Fig. $\left.8 A, B\right)$. The animals were tested on 1 and 7 dpo and then every 3-4 d during the recovery period (Fig. $8 A, B$ ). The experiment was terminated at $45 \mathrm{dpo}$, when all animals had regained a normal grip. Animals were tested at 1 dpo to confirm the completeness of the nerve crush. At 7 dpo, 

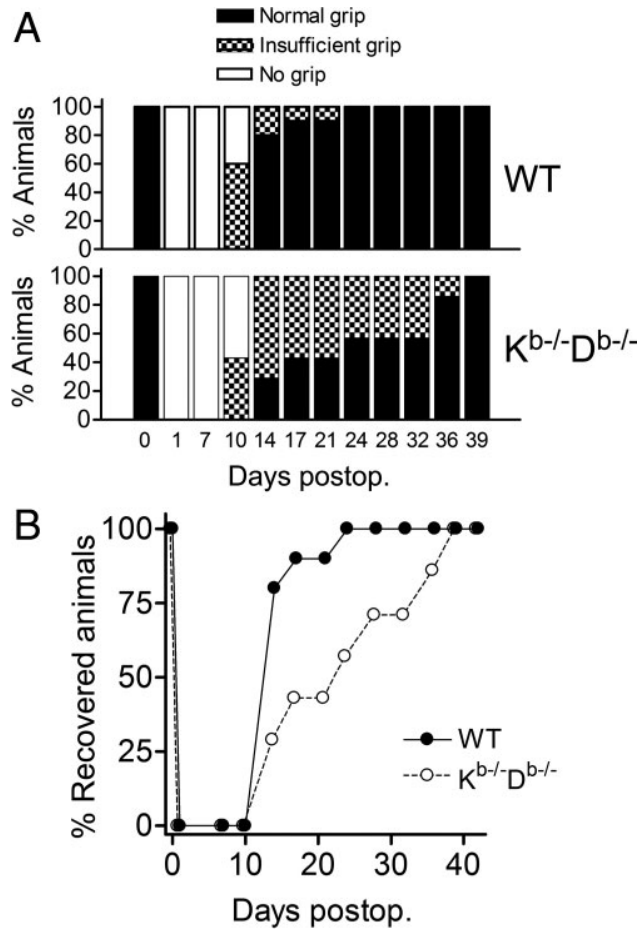

Figure 8. Impaired motor recovery in MHC class la-deficient mice after SNC. $A$, A time course analysis showing the percentage of WT and $K^{b-/-} D^{b-/-}$ mice with normal grip, insufficient grip, or no grip before operation and during the recovery period after SNC. $\boldsymbol{B}$, The progression of the animals to complete recovery (i.e., normal grip).

no animal was able to grip a metal rod placed on the soles of the hindfeet (no grip; see Materials and Methods). At 10 dpo, 60\% the WT mice and $43 \%$ of the $K^{b-1-} D^{b-1-}$ mice had an insufficient grip. All animals in both groups were able to grip the metal bar at 14 dpo; however, in the WT group, $80 \%$ of the animals had a normal grip and $20 \%$ still had an insufficient grip, whereas only $29 \%$ of the $K^{b-/-} D^{b-/-}$ mice had regained a normal grip and $71 \%$ displayed an insufficient grip. The WT mice then progressed rapidly at the following time points, and, at $24 \mathrm{dpo}$, all WT animals had recovered a normal grip. The $K^{b-/-} D^{b-1-}$ group recovered considerably more slowly, and all animals were not fully recovered until $15 \mathrm{~d}$ later, i.e., $39 \mathrm{dpo}$ (Fig. $8 B$ ).

\section{Discussion}

\section{Expression of MHC class I molecules in motoneurons}

The aim of this study was to characterize the expression, subcellular localization, and function of MHC class Ia proteins in spinal motoneurons, under normal conditions and during reinnervation after injury. From the in situ hybridization results, we anticipated a strongly increased MHC class Ia-IR in axotomized motoneuron somata, as reported previously for rat sciatic motoneurons after peripheral nerve lesion (Maehlen et al., 1989). However, to our surprise, the difference in $\mathrm{H} 2-\mathrm{D}^{\mathrm{b}}$-IR in the somata of axotomized motoneurons compared with intact motoneurons was subtle. Furthermore, $\mathrm{H} 2-\mathrm{D}^{\mathrm{b}}$-IR was not detected in motoneuron dendrites. In contrast, a profound increase in $\mathrm{H} 2-\mathrm{D}^{\mathrm{b}}$-IR was observed in activated microglia surrounding the axotomized motoneurons. There was thus a clear discrepancy between the changes in mRNA levels and the $\mathrm{H} 2-\mathrm{D}^{\mathrm{b}}$-IR in motoneuron somata and dendrites after axotomy. A strong H2$\mathrm{D}^{\mathrm{b}}$-IR was detected in motor axons, however, suggesting that $\mathrm{H} 2-\mathrm{D}^{\mathrm{b}}$ molecules were subjected to anterograde axonal transport. Such transport for neuronal MHC class I molecules has been described in the vomeronasal system in vivo (Ishii and Mombaerts, 2008), cortical and hippocampal neurons in vitro (Medana et al., 2001; Taylor et al., 2009), and further indicated in a mouse model of neuroinflammation (Rivera-Quinones et al., 1998).

Thus, instead of identifying $\mathrm{H} 2-\mathrm{D}^{\mathrm{b}}$ as a putative postsynaptic protein, as anticipated from a previous publication (Goddard et al., 2007), its presence in motor axons and at NMJs rather suggests an interaction with elements in the peripheral nerve and possibly also with postsynaptic elements in muscle fibers. A presynaptic role for $\mathrm{H} 2-\mathrm{D}^{\mathrm{b}}$ in motoneurons is supported by the finding of a perturbed organization of NMJs in absence of MHC class Ia molecules.

The observed heterogeneity of the $\mathrm{H} 2-\mathrm{K}^{\mathrm{b}} / \mathrm{D}^{\mathrm{b}}$ mRNA expression in motoneurons was a striking finding, which was also reflected in a variation of $\mathrm{H} 2-\mathrm{D}^{\mathrm{b}}$-IR in NMJs. Motoneurons and the muscle fibers innervated by them (motor units) show distinct excitability and recruitment properties of the motoneurons and likewise distinct properties of muscle fiber force and fatigue. These differences have led to a classification of motoneurons and motor units into fast-twitch fatiguable, fast-twitch fatigue resistant, and slow twitch (Burke et al., 1971). Individual muscles usually have a mixture of motor unit types, and thus there is a possibility that the variation in classical MHC class I levels seen here is related to motor unit type.

\section{MHC class Ia proteins and NMJ plasticity}

Initially during normal development, skeletal muscles are hyperinnervated, i.e., several terminals can contact a single muscle fiber and the density of NMJs is greater than in the adult stage (Sanes and Lichtman, 1999; Song et al., 2006; Witzemann, 2006). As a consequence of synaptic pruning and refinement, individual muscle fibers eventually receive exclusive innervation from one motoneuron at a single receptor site in the adult stage (Gan and Lichtman, 1998; Sanes and Lichtman, 1999; Kim and Burden, 2008). This competition between neuronal inputs to the muscle fibers is activity dependent (Sanes and Lichtman, 1999; Song et al., 2006), and it is thus intriguing to draw parallels to the function of MHC class I molecules in activity-dependent plasticity in the retinogeniculate system, as proposed by Corriveau et al. (1998).

During muscle reinnervation after a nerve lesion, a process similar to developmental synaptic elimination after initial reinnervation phase is required in the muscle. We here show that MHC class I molecules appear to be involved in regulating the density of NMJs during muscle reinnervation. This effect could be mediated by excessive formation, impaired elimination, or continuous remodeling of NMJs. Because we detected the presence of individual muscle fibers in adult uninjured $K^{b-/-} D^{b-/-}$ mice with more than one AChR clusters, an impaired elimination during development could offer a possible explanation to the observed higher density of NMJs in the absence of MHC class I. Such a mechanism could also explain the abnormal dynamic changes in NMJ density seen in the $\mathrm{K}^{b-/-} D^{b-/-}$ mice during reinnervation after the hyperinnervation phase. This could in turn underlie the observed delayed return of grip ability in $\mathrm{K}^{b-1-} D^{b-/-}$ animals.

\section{Possible MHC class I-dependent interactions in motoneuron axons}

The accumulating reports of MHC class I function in neurons have initiated a search for putative neuronal MHC class I receptors in the CNS and PNS. Possible candidates with mRNA expres- 
sion or immunoreactivity in neurons include the TCR-CD3 complex (Huh et al., 2000; Syken and Shatz, 2003), the paired Ig receptor PIR-B (Syken et al., 2006), members of the Ly-49 receptor family (Zohar et al., 2008), and receptors associated with DAP12 (Roumier et al., 2004). Several of these candidates have been linked to synaptic plasticity or function in the CNS (Huh et al., 2000; Roumier et al., 2004; Syken et al., 2006; Zohar et al., 2008). Moreover, neuronally expressed PIR-B was recently reported to mediate interactions between outgrowing axons and inhibitory myelin associated proteins, such as Nogo, MAG, and oligodendrocyte myelin glycoprotein (Atwal et al., 2008).

In skeletal muscles, there are several cell types that could express a receptor for MHC class I molecules. Immune cells infiltrate muscles during inflammation and trauma and could be potential candidates. However, because the $\mathrm{H} 2-\mathrm{K}^{\mathrm{b}} / \mathrm{D}^{\mathrm{b}}$-dependent synaptic phenotype appears to be absent in the immunodeficient $R A G 1^{-/-}$strain, it is not likely that $\mathrm{T}$ - or $\mathrm{B}$-cells are responsible for the synaptic disturbances seen in $K^{b-/-} D^{b-/-}$ mice. This does not exclude a role for cells of the constitutive immune system, such as macrophages, NK-cells, and dendritic cells.

The NMJ is a triparte organization consisting of postsynaptic AChRs on the muscle fibers, a presynaptic motor terminal, and TSCs (Sanes and Lichtman, 1999; Reddy et al., 2003). The TSCs provide stability, produce growth factors, and are involved in synapse homeostasis (Sanes and Lichtman, 1999; Reddy et al., 2003; Feng and Ko, 2007). In general, SCs participate in axon guidance, synaptic formation during development, and regeneration after nerve injury (Love and Thompson, 1998; Magill et al., 2007). Interestingly, SCs can control the number of NMJs and can remove superfluous presynaptic terminals (Bishop et al., 2004; Song et al., 2008). During reinnervation after nerve crush, SCs proliferate and one important function is to participate in the removal of inappropriate presynaptic terminals (Song et al., 2008). In $K^{b-1-} D^{b-1-}$ mice, fewer TSCs are associated with individual synapses at both intact and reinnervated NMJs, suggesting a defect in SC recruitment or proliferation. Impaired interactions between axons and SCs could then partly explain the inaccuracy of synaptic band formation observed in $\mathrm{K}^{b-/-} D^{b-/-}$ mice. Furthermore, a decreased removal of synapses by SCs could consequently result in a higher density of NMJs. These cells were therefore possible candidates at the NMJ for expressing receptors interacting with neuronal MHC class Ia molecules. Interestingly, we detected surface expression of PIR-B in a subpopulation of dissociated SCs from peripheral nerves using FACS as well as PIR-B expression in SCs in vivo in the sciatic nerve. This finding provides a basis for a possible MHC class I-mediated signaling between neurons and SCs. The apparent lack of PIR-B-IR in TSCs may suggest an interaction between MHC class I and SCs proximal to the NMJ. This could still influence the NMJ-TSC relationship, because TSCs proliferate from distal immature SCs during reinnervation (Jessen and Mirsky, 2005; Magill et al., 2007).

The aim of this study was to identify nonimmune consequences of the fact that motoneurons harbor MHC class Ia molecules. The presented findings, however, do not rule out that the presence of classical MHC class I in motor axons and NMJs could also be of relevance for the established function for these molecules, i.e., antigen presentation to immune cells. Thus, it may be speculated that the exposure of classical MHC class I molecules loaded with "self" or "non-self" peptides on peripheral motor axons may induce an immune response with adverse effects on motoneurons. This, in turn, is of interest in relation to the emerging focus on axonal and synaptic pathology as early signs and even as key triggering factors for the onset of neurodegenerative disease (Raff et al., 2002; Selkoe, 2002; Conforti et al., 2007; Gould and Oppenheim, 2007; Saxena and Caroni, 2007). In this context, it is of interest that MHC class I mRNA has been detected in all peripheral motoneuron groups, except for the ocular motor nuclei, which are known to be spared in the motoneuron neurodegenerative disorder amyotrophic lateral sclerosis (Lindå et al., 1999).

In summary, we have here shown that the classical MHC class I products are expressed in axons and axon terminals of motoneurons. Moreover, in the absence of classical MHC class I expression, the organization of the NMJs formed by the motor axon terminals is disturbed, and the motor recovery after nerve lesion is delayed. These effects are in line with the emerging concept that immune molecules are used in the nervous system for other or additional purposes compared with the immune system, in particular related to synaptic function and plasticity. Our study is the first, to our knowledge, to indicate a presynaptic role for MHC class I molecules on synaptic organization.

\section{References}

Atwal JK, Pinkston-Gosse J, Syken J, Stawicki S, Wu Y, Shatz C, TessierLavigne M (2008) PirB is a functional receptor for myelin inhibitors of axonal regeneration. Science 322:967-970.

Bishop DL, Misgeld T, Walsh MK, Gan WB, Lichtman JW (2004) Axon branch removal at developing synapses by axosome shedding. Neuron 44:651-661.

Blinzinger K, Kreutzberg G (1968) Displacement of synaptic terminals from regenerating motoneurons by microglial cells. Z Zellforsch Mikrosk Anat 85:145-157.

Burke RE, Levine DN, Zajac FE 3rd (1971) Mammalian motor units: physiological-histochemical correlation in three types in cat gastrocnemius. Science 174:709-712.

Conforti L, Adalbert R, Coleman MP (2007) Neuronal death: where does the end begin? Trends Neurosci 30:159-166.

Corriveau RA, Huh GS, Shatz CJ (1998) Regulation of class I MHC gene expression in the developing and mature CNS by neural activity. Neuron 21:505-520.

Dagerlind A, Friberg K, Bean AJ, Hökfelt T (1992) Sensitive mRNA detection using unfixed tissue: combined radioactive and non-radioactive in situ hybridization histochemistry. Histochemistry 98:39-49.

Feng Z, Ko CP (2007) Neuronal glia interactions at the vertebrate neuromuscular junction. Curr Opin Pharmacol 7:316-324.

Gan WB, Lichtman JW (1998) Synaptic segregation at the developing neuromuscular junction. Science 282:1508-1511.

Goddard CA, Butts DA, Shatz CJ (2007) Regulation of CNS synapses by neuronal MHC class I. Proc Natl Acad Sci U S A 104:6828-6833.

Gould TW, Oppenheim RW (2007) Synaptic dysfunction in disease and following injury in the developing and adult nervous system: caveats in the choice of therapeutic intervention. Neurosci Biobehav Rev 31:1073-1087.

Hess DM, Scott MO, Potluri S, Pitts EV, Cisterni C, Balice-Gordon RJ (2007) Localization of TrkC to Schwann cells and effects of neurotrophin-3 signaling at neuromuscular synapses. J Comp Neurol 501:465-482.

Hirata H, Hibasami H, Yoshida T, Ogawa M, Matsumoto M, Morita A, Uchida A (2001) Nerve growth factor signaling of p75 induces differentiation and ceramide-mediated apoptosis in Schwann cells cultured from degenerating nerves. Glia 36:245-258.

Huh GS, Boulanger LM, Du H, Riquelme PA, Brotz TM, Shatz CJ (2000) Functional requirement for class I MHC in CNS development and plasticity. Science 290:2155-2159.

Ishii T, Mombaerts P (2008) Expression of nonclassical class I major histocompatibility genes defines a tripartite organization of the mouse vomeronasal system. J Neurosci 28:2332-2341.

Jessen KR, Mirsky R (2005) The origin and development of glial cells in peripheral nerves. Nat Rev Neurosci 6:671-682.

Kim N, Burden SJ (2008) MuSK controls where motor axons grow and form synapses. Nat Neurosci 11:19-27.

Kimura T, Griffin DE (2000) The role of CD8(+) T cells and major histo- 
compatibility complex class I expression in the central nervous system of mice infected with neurovirulent Sindbis virus. J Virol 74:6117-6125.

Laskowski MB, Norton AS, Berger PK (1991) Branching patterns of the rat phrenic nerve during development and reinnervation. Exp Neurol 113:212-220.

Lindå H, Hammarberg H, Cullheim S, Levinovitz A, Khademi M, Olsson T (1998) Expression of MHC class I and beta2-microglobulin in rat spinal motoneurons: regulatory influences by IFN-gamma and axotomy. Exp Neurol 150:282-295.

Love FM, Thompson WJ (1998) Schwann cells proliferate at rat neuromuscular junctions during development and regeneration. J Neurosci 18:9376-9385.

Maehlen J, Nennesmo I, Olsson AB, Olsson T, Daa Schröder H, Kristensson K (1989) Peripheral nerve injury causes transient expression of MHC class I antigens in rat motor neurons and skeletal muscles. Brain Res $481: 368-372$.

Magill CK, Tong A, Kawamura D, Hayashi A, Hunter DA, Parsadanian A, Mackinnon SE, Myckatyn TM (2007) Reinnervation of the tibialis anterior following sciatic nerve crush injury: a confocal microscopic study in transgenic mice. Exp Neurol 207:64-74.

Medana I, Martinic MA, Wekerle H, Neumann H (2001) Transection of major histocompatibility complex class I-induced neurites by cytotoxic $\mathrm{T}$ lymphocytes. Am J Pathol 159:809-815.

Oliveira AL, Thams S, Lidman O, Piehl F, Hökfelt T, Kärre K, Lindå H, Cullheim S (2004) A role for MHC class I molecules in synaptic plasticity and regeneration of neurons after axotomy. Proc Natl Acad Sci U S A 101:17843-17848.

Paratcha G, Ledda F, Baars L, Coulpier M, Besset V, Anders J, Scott R, Ibáñez CF (2001) Released GFRalpha1 potentiates downstream signaling, neuronal survival, and differentiation via a novel mechanism of recruitment of c-Ret to lipid rafts. Neuron 29:171-184.

Pascolo S, Bervas N, Ure JM, Smith AG, Lemonnier FA, Pérarnau B (1997) HLA-A2.1-restricted education and cytolytic activity of CD8(+) T lymphocytes from beta2 microglobulin (beta2m) HLA-A2.1 monochain transgenic $\mathrm{H}-2 \mathrm{Db}$ beta2 $\mathrm{m}$ double knockout mice. J Exp Med 185:2043-2051.

Pérarnau B, Saron MF, San Martin BR, Bervas N, Ong H, Soloski MJ, Smith AG, Ure JM, Gairin JE, Lemonnier FA (1999) Single H2Kb, H2Db and double $\mathrm{H} 2 \mathrm{KbDb}$ knockout mice: peripheral $\mathrm{CD} 8+\mathrm{T}$ cell repertoire and anti-lymphocytic choriomeningitis virus cytolytic responses. Eur J Immunol 29:1243-1252.

Piehl F, Ji RR, Cullheim S, Hökfelt T, Lindholm D, Hughes RA (1995) Fibroblast growth factors regulate calcitonin gene-related peptide mRNA expression in rat motoneurons after lesion and in culture. Eur J Neurosci 7:1739-1750.

Raff MC, Whitmore AV, Finn JT (2002) Axonal self-destruction and neurodegeneration. Science 296:868-871.

Reddy LV, Koirala S, Sugiura Y, Herrera AA, Ko CP (2003) Glial cells maintain synaptic structure and function and promote development of the neuromuscular junction in vivo. Neuron 40:563-580.

Rivera-Quiñones C, McGavern D, Schmelzer JD, Hunter SF, Low PA, Rodriguez M (1998) Absence of neurological deficits following extensive de- myelination in a class I-deficient murine model of multiple sclerosis. Nat Med 4:187-193.

Roumier A, Béchade C, Poncer JC, Smalla KH, Tomasello E, Vivier E, Gundelfinger ED, Triller A, Bessis A (2004) Impaired synaptic function in the microglial KARAP/DAP12-deficient mouse. J Neurosci 24:1142111428.

Salazar-Grueso EF, Kim S, Kim H (1991) Embryonic mouse spinal cord motor neuron hybrid cells. Neuroreport 2:505-508.

Sanes JR, Lichtman JW (1999) Development of the vertebrate neuromuscular junction. Annu Rev Neurosci 22:389-442.

Saxena S, Caroni P (2007) Mechanisms of axon degeneration: from development to disease. Prog Neurobiol 83:174-191.

Selkoe DJ (2002) Alzheimer's disease is a synaptic failure. Science 298: 789-791.

Song JW, Misgeld T, Kang H, Knecht S, Lu J, Cao Y, Cotman SL, Bishop DL, Lichtman JW (2008) Lysosomal activity associated with developmental axon pruning. J Neurosci 28:8993-9001.

Song Y, Panzer JA, Wyatt RM, Balice-Gordon RJ (2006) Formation and plasticity of neuromuscular synaptic connections. Int Anesthesiol Clin 44:145-178.

Stevens B, Allen NJ, Vazquez LE, Howell GR, Christopherson KS, Nouri N, Micheva KD, Mehalow AK, Huberman AD, Stafford B, Sher A, Litke AM, Lambris JD, Smith SJ, John SW, Barres BA (2007) The classical complement cascade mediates CNS synapse elimination. Cell 131:1164-1178.

Syken J, Shatz CJ (2003) Expression of T cell receptor beta locus in central nervous system neurons. Proc Natl Acad Sci U S A 100:13048-13053.

Syken J, Grandpre T, Kanold PO, Shatz CJ (2006) PirB restricts oculardominance plasticity in visual cortex. Science 313:1795-1800.

Taylor AM, Berchtold NC, Perreau VM, Tu CH, Li Jeon N, Cotman CW (2009) Axonal mRNA in uninjured and regenerating cortical mammalian axons. J Neurosci 29:4697-4707.

Tsuyuki Y, Fujimaki H, Hikawa N, Fujita K, Nagata T, Minami M (1998) IFN-gamma induces coordinate expression of MHC class I-mediated antigen presentation machinery molecules in adult mouse Schwann cells. Neuroreport 9:2071-2075.

Ulfhake B, Cullheim S (1988) Postnatal development of cat hind limb motoneurons. III. Changes in size of motoneurons supplying the triceps surae muscle. J Comp Neurol 278:103-120.

Verdu E, Navarro X (1997) Comparison of immunohistochemical and functional reinnervation of skin and muscle after peripheral nerve injury. Exp Neurol 146:187-198.

Vugmeyster Y, Glas R, Pérarnau B, Lemonnier FA, Eisen H, Ploegh H (1998) Major histocompatibility complex (MHC) class I $\mathrm{KbDb}-/-$ deficient mice possess functional CD8 $+\mathrm{T}$ cells and natural killer cells. Proc Natl Acad Sci U S A 95:12492-12497.

Witzemann V (2006) Development of the neuromuscular junction. Cell Tissue Res 326:263-271.

Zelano J, Wallquist W, Hailer NP, Cullheim S (2006) Expression of nectin-1, nectin-3, N-cadherin, and NCAM in spinal motoneurons after sciatic nerve transection. Exp Neurol 201:461-469.

Zohar O, Reiter Y, Bennink JR, Lev A, Cavallaro S, Paratore S, Pick CG, Brooker G, Yewdell JW (2008) Cutting edge: MHC class I-ly49 interaction regulates neuronal function. J Immunol 180:6447-6451. 